\title{
The citrullinated/native index of autoantibodies against hnRNP-DL predicts an individual "window of treatment success" in RA patients
}

Bianka Marklein ${ }^{1}$, Madeleine Jenning ${ }^{1,2}$, Zoltán Konthur ${ }^{3,4,5}$, Thomas Häupl ${ }^{1}$, Franziska Welzel ${ }^{3}$, Ute Nonhoff ${ }^{3}$, Sylvia Krobitsch ${ }^{3}$, Debbie M. Mulder ${ }^{6}$, Marije I. Koenders ${ }^{6}$, Vijay Joshua ${ }^{7}$, Andrew P. Cope ${ }^{8}$, Mark J. Shlomchik ${ }^{9}$, Hans-Joachim Anders ${ }^{10}$, Gerd R. Burmester ${ }^{1}$, Aase Hensvold ${ }^{7,11}$, Anca I. Catrina ${ }^{7}$, Johan Rönnelid ${ }^{12}$, Günter Steiner ${ }^{13,14}$ and Karl Skriner ${ }^{1,2^{*}}$ (D)

\section{Abstract}

Background: There is a need for biomarker to identify patients "at risk" for rheumatoid arthritis (risk-RA) and to better predict the therapeutic response and in this study we tested the hypothesis that novel native and citrullinated heterogeneous nuclear ribonucleoprotein (hnRNP)-DL autoantibodies could be possible biomarkers.

Methods: Using protein macroarray and ELISA, epitope recognition against hnRNP-DL was analysed in sera from different developed RA disease and diagnosed SLE patients. Toll-like receptor (TLR) 7/9 and myeloid differentiation primary response gene 88 (MyD88)-dependency were studied in sera from murine disease models. HnRNP-DL expression in cultivated cells and synovial tissue was analysed by indirect immunofluorescence, immunoblot and immunohistochemistry.

\footnotetext{
* Correspondence: karl.skriner@charite.de

'Department of Rheumatology and Clinical Immunology, Charité Universitätsmedizin Berlin, Charite Campus Mitte, Rheumatologisches Forschungslabor - AG Skriner, Chariteplatz 1 (intern Virchowweg 11, 5.OG, R011), 10117 Berlin, Germany

${ }^{2}$ German Rheumatism Research Centre, Leibniz Institute, 10117 Berlin, Germany

Full list of author information is available at the end of the article
}

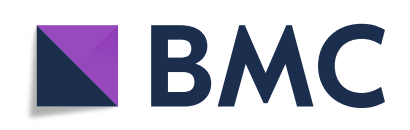

(- The Author(s). 2021, corrected publication 2021. Open Access This article is licensed under a Creative Commons Attribution 4.0 International License, which permits use, sharing, adaptation, distribution and reproduction in any medium or format, as long as you give appropriate credit to the original author(s) and the source, provide a link to the Creative Commons licence, and indicate if changes were made. The images or other third party material in this article are included in the article's Creative Commons licence, unless indicated otherwise in a credit line to the material. If material is not included in the article's Creative Commons licence and your intended use is not permitted by statutory regulation or exceeds the permitted use, you will need to obtain permission directly from the copyright holder. To view a copy of this licence, visit http://creativecommons.org/ licenses/by/4.0/. The Creative Commons Public Domain Dedication waiver (http://creativecommons.org/publicdomain/zero/1. 0/) applies to the data made available in this article, unless otherwise stated in a credit line to the data. 
Results: HnRNP-DL was highly expressed in stress granules, citrullinated in the rheumatoid joint and targeted by autoantibodies either as native or citrullinated proteins in patient subsets with different developed RA disease. Structural citrullination dependent epitopes (SCEs) of hnRNP-DL were detected in 58\% of the SLE patients although $98 \%$ of these sera were a-CCP-2-negative. To obtain a specific citrullinated signal value, we subtracted the native antibody value from the citrullinated signal. The citrullinated/native index of autoantibodies against hnRNP-DL ( $C N_{D L}-$ Index) was identified as a new value for an "individual window of treatment success" in early RA and for the detection of RF IgM/a-CCP-2 seronegative RA patients (24-46\%). Negative $C N_{D L}$-index was found in SLE patients, risk-RA and early RA cohorts such as EIRA where the majority of these patients are DAS28-responders to methotrexate (MTX) treatment (87\%). High positive $\mathrm{CN}_{\mathrm{DL}}$-values were associated with more severe RA, shared epitope and parenchymal changes in the lung. Specifically, native a-hnRNP-DL is TLR7/9-dependent, associated with pain and ROC analysis revealed an association to initial MTX or etanercept treatment response, especially in seronegative RA patients.

Conclusion: $\mathrm{CN}_{\mathrm{DL}}$-index defines people at risk to develop RA and the "window of treatment success" thereby closing the sensitivity gap in RA.

Keywords: Rheumatoid arthritis, ACPA, Anti-CCP, Rheumatoid factor, Shared epitope, Systemic lupus erythematosus, Autoantigens, Treatment

\section{Background}

More than 20 years ago heterogeneous nuclear ribonucleoprotein (hnRNP) complexes were first described as autoimmune targets [1, 2]. These complexes associate with DNA and RNA and can stimulate Toll-like receptor (TLR) 7 and 9 [3-7]. Antibodies against these structures are characteristic for autoimmune disorders, such as systemic lupus erythematosus (SLE), progressive systemic sclerosis (scleroderma), primary Sjögren's syndrome, HTLV-1-associated myelopathy/tropical spastic paraparesis (HAM/TSP), multiple sclerosis (MS) and rheumatoid arthritis (RA) as well as for mouse models of lupus and arthritis [8-10].

In $\mathrm{RA}$, the most specific anti-nuclear reactivity is directed against hnRNPs. Most prominent targets are hnRNP-A1 and hnRNP-A2/B1 proteins, which with hnRNP-A3 and hnRNP-A0 proteins form the subgroup of hnRNP-A/B proteins [11-15]. Autoantibodies against hnRNP-A2/B1 (RA33) occur in about $20-40 \%$ of RA, SLE and mixed connective tissue disease (MCTD) patients [16]. Autoantibodies to hnRNP-A1 can be found in RA, SLE and MCTD, but probably are cross-reacting $\alpha$-hnRNP-A2/B1 antibodies [17]. Also, hnRNP-A2/B1 is citrullinated in the rheumatoid joint, and it can be targeted either as a citrullinated and or native protein in distinct subsets of RA patients [18].

Previously, we have described autoantibodies directed to the TNF $\alpha$ regulatory protein hnRNP-D (AUF1) to occur in $33 \%$ of SLE, $20 \%$ of RA and $17 \%$ of MCTD patients [19]. Although predominantly localized in the nucleus, hnRNPs are exported additionally into the cytosol, where they form new autoimmune target structures in stress granules, P-bodies or RNA transport particles [19-21].
The hnRNP-D-like protein (hnRNP-DL) protein, which is also known as JKTBP, is related to the autoantigen hnRNP-D/AUF1. Due to its binding properties and structural features [22], hnRNP-DL,-D and -AB- form the D-subgroup of hnRNPs. These proteins exhibit a modular structure and conserved residues, two adjacent RNA binding domains (RBD) followed by a glycine-rich $\mathrm{C}$-terminal auxiliary domain. However, they are very distinct in each of the unique N-terminal regions [23, 24].

HnRNP-DL acts as a transcription factor [25], participates in metabolism and biogenesis of mRNA [3], is able to shuttle between the nucleus and the cytoplasm and binds both to nuclear and cytoplasmic mRNAs [24], especially when containing AU-rich elements (AREs) as found within the 3'-UTR of many proto-oncogenes and cytokine mRNAs [26, 27]. Up to now, three alternatively spliced hnRNP-DL transcript variants have been described, hnRNP-DL isoform 1-3, whereas proteins only were described for isoform 1 and 2 [23]. Splenocytes from pristane-primed rats restimulated with hnRNPs (-A1,-A2/ $\mathrm{B} 1$ and -A3) induce a highly inflammatory and erosive arthritis in naive recipient rats [6]. Furthermore, human $\mathrm{TNF} \alpha$-transgenic mice, which develop a massive erosive inflammatory polyarthritis, generate $\alpha$-hnRNP autoantibodies [28]. This supports the hypothesis of a pathogenic role of native hnRNPs in erosive arthritis and suggests that autoimmunity to nucleic acid-associated autoantigens has the potential to contribute to RA development [18]. HnRNPs may also induce pro-inflammatory cytokines, relevant for arthritis development in rats, which involve TLR7 and TLR9 but not TLR4 [6].

For $\alpha$-hnRNP-A2/B1, clinical associations have already been shown for RA severity, with antibodies against the citrullinated protein occurring more frequently in 
erosive RA and antibodies against the native protein in milder disease $[18,29]$. For citrullinated peptides, it has already been shown that the formation of a delta value with the corresponding arginine peptide increased diagnostic sensitivity and indicated association to shared epitope (SE) [30].

In our study, the delta value of ELISA signals was evaluated as a possible biomarker to obtain a new clinical value, as the difference between the $\alpha$-citrullinated and $\alpha$-native protein value. hnRNPs were further investigated in the immunopathogenesis of RA, demonstrating the clinical relevance of autoantibodies, for predicting therapeutic success, early parenchymal changes in the lung, and SE in RA. For the first time, structural epitopes resulting from the citrullination process were investigated.

\section{Material and methods}

\section{Patient sera}

A total of 1010 sera were evaluated, including patients with early RA (EIRA cohort $n=404$ ), early RA with lung association (LURA cohort $n=106$ ), established rheumatoid arthritis (predict cohort $n=127$ ), systemic lupus erythematosus $(n=89)$, multiple sclerosis $(n=20)$, reactive arthritis $(n=7)$, scleroderma $(n=20)$, Sjögren's syndrome $(n=20)$, psoriasis arthritis $(n=20)$, ankylosing spondylitis $(n=20)$, osteoarthritis $(n=20)$, people at risk for developing RA (Risk-RA cohort from Sweden $n$ $=62$; Risk-RA from Erlangen $n=9$ ) and healthy control subjects $(n=86)$. The sera were derived from the serum bank of the 2nd Department of Medicine-Centre of Rheumatic Diseases, Hiezing Hospital (Vienna, Austria), and of the Department of Rheumatology at the Charite Universitätsmedizin (Berlin, Germany). Early RA sera from the Swedish EIRA [31] and LURA [32] cohort and Risk-RA patients were provided by the early arthritis clinic of Karolinska University Hospital in Stockholm, Sweden. Further, we obtained sera from Risk-RA also from the Institute of Rheumatology and Immunology of the University of Erlangen, Germany.

All patients with RA fulfilled the 1987 revised criteria of the American College of Rheumatology [33]. All patients with SLE met the 1982 criteria of the ACR [34], and all patients with MCTD met the criteria described by Alarcon-Segovia and Villarreal [35].

\section{Mice sera}

A total of 153 mice sera were evaluated. SKG Zymosan model ( $n=16$; King's College, London, England), MRL/ $\operatorname{lpr}(n=20)$, MRL lpr MyD88 ${ }^{-1-}(n=20)$, MRL/lpr $\mathrm{TLR7}^{-1-}(n=7), \mathrm{MRL} / \mathrm{lpr} \mathrm{TLR}^{-/-}(n=4), \mathrm{MRL} / \mathrm{lpr}$ TLR7/ $/ 9^{-1-}(n=7$, all 5 from Yale University School of Medicine, New Haven), C57BL/6 lpr $(n=12)$, C57BL/6 lpr SIGIRR/TIR8 ${ }^{-1-}(n=12$, both from Medical Policlinics, University Munich), C57BL/6 $(n=10)$, C57BL $/ 6$
+R848 ( $n=10$, both from University Hospital of Zurich, Zurich, Switzerland), and Balb/c IL- $1 \mathrm{Ra}^{-1-}(n=35$, Radboud University Medical Center 272, Experimental Rheumatology Nijmegen, The Netherlands).

\section{Cell lines}

HEp-2 cell slides were supplied by Generic Assays (ANA HEp-2 plus Kit; Generic Assays, Dahlewitz, Germany), IL1 $\alpha-$, TNF $\alpha$ - and non-stimulated HeLa whole cell extracts and IL6- and non-stimulated HepG2 whole cell extract were obtained by Active Motif (Carlsbad, USA). Ten microgrammes cell extract per lane were separated on a SDS-gel and transferred to a nitrocellulose membrane.

\section{Protein macroarray}

Screening for novel autoantigens in RA was performed on $\mathrm{hEX} 1$ protein macroarrays derived from CDNA of human foetal brain [36] (available from engine $\mathrm{GmbH}$, Hennigsdorf, Germany). Screening was carried out as described by the manufacturer. Briefly, protein macroarrays were incubated with blocking buffer $(3 \%(\mathrm{w} / \mathrm{v})$ milk powder in TBST $(500 \mathrm{mM} \mathrm{NaCl}, 20 \mathrm{mM}$ Tris- $\mathrm{HCl}, \mathrm{pH}$ $7.5,0.05 \%$ Tween 20)) for $1 \mathrm{~h}$ at room temperature followed by overnight incubation at $4{ }^{\circ} \mathrm{C}$ with patient serum (1:50 dilution in blocking buffer). Subsequently, arrays were washed three times for $20 \mathrm{~min}$ each, in TBST-T (TBS with $0.05 \%$ Triton X-100) and incubated $2 \mathrm{~h}$ at room temperature with an alkaline phosphatase (AP)-conjugated goat $\alpha$-human IgG antibody (A9544, Sigma-Aldrich, St. Louis, USA) in blocking buffer for 2 h. Following three washes for $20 \mathrm{~min}$ in TBST-T, the arrays were incubated for $10 \mathrm{~min}$ in AP-buffer $(1 \mathrm{mM}$ $\mathrm{MgCl}_{2}, 100 \mathrm{mM}$ Tris-Cl, pH 9.5) and finally $5 \mathrm{~min}$ in $0.125 \mathrm{mM}$ Attophos (Roche, Basel, Switzerland) in APbuffer. Arrays were illuminated with an excitation wavelength of $460 \mathrm{~nm}$ and images were taken using a CCD camera (Fuji LAS 1000, Tokyo, Japan). Image analysis was performed with AIDA software (Raytest, Berlin, Germany). The manufacturer has defined the cutoff values according to Aida program. Each filter has an individual cutoff level defined by signals of individual dots without expression vector and dots without bacteria.

Positive positions on the arrays were scored and correlated with clone data provided by the manufacturer.

\section{Cloning, expression and purification of recombinant fusion proteins}

Recombinant hnRNP-DL (UniProt NP_112740.1) was expressed in two bacterial clones with different variants of hnRNP-DL (amino acid 81-420 or 120-420). The hnRNP-D (AUF1) isoform p45, cloned in pTrcHis vector (Life Technologies; Carlsbad, USA), was a kind gift by Gary Brewer (School of Medicine, Wake Forest 
University, USA). The AUF1 p45 plasmid includes the longest transcript variant of AUF1 (UniProt NP 112738.1) and consists of 322 amino acids $(45 \mathrm{kDa})$. For expression, the AUF1p45 plasmid was transformed into expression strain BL21 (DE3) pLysS cells (Merck Millipore; Darmstadt, Germany, USA) according to the manufacturer's protocol.

The cDNA clone of hnRNP-DL was obtained from (IRAUp969E0262D, Source BioScience, Nottingham, UK). The polymerase chain reaction was performed, using the oligonucleotides primer 1: GACGACGACAAGATGGAGGT CCCGCCCAG and primer 2: GAGGAGAAGCCCGG TTAGTATGGCTGGTAATTG as primers (Biolegio, Nijmegan, Netherlands). The hnRNP-DL sequence was cloned using pET-30 Ek/LIC vector kit (Merck Millipore, Billerica, USA). Insert sequences were checked by sequencing (LGC Genomics, Berlin, Germany).

For protein expression, 1 L LB medium (containing antibiotics corresponding to the carrying expression vector) was inoculated with $5 \mathrm{~mL}$ overnight culture of the expression strain (E. coli LysS or -SCS1) and incubated at $37{ }^{\circ} \mathrm{C}$ with shaking until optical density of the solution was within the range of $\mathrm{OD}_{600}$ 0.4-0.6. Fusion protein expression was induced by adding IPTG to a final concentration of $1 \mathrm{mM}$. After $4 \mathrm{~h}$, the bacterial cells were pelleted at $20.000 \times g$ for 10 min and stored at $-20{ }^{\circ} \mathrm{C}$.

All proteins were expressed as His-tag fusions proteins and purified by HisPur Cobalt Resin (Thermo Fisher Scientific, Rockford, USA) in a batch process corresponding to the manufacturer's protocol under denaturing conditions (hnRNP-DL/ AUF1).

\section{Enzyme-linked immunosorbent assay (ELISA)}

ELISA plates (Nunc 96-well Nunc Maxisorp; Nalgene Nunc International, Rochester, NY, $1 \mu \mathrm{g}$ protein/ well) were coated with recombinant proteins in PBS by passive adsorption at $4{ }^{\circ} \mathrm{C}$, overnight. For sample background control plates were incubated with coating buffer only.

After washing three times with washing buffer $(0.1 \%$ Tween 20 in PBS, pH 7.4, $300 \mu \mathrm{L} /$ well) and blocking with blocking buffer (5\% non-fat dried milk in PBS, $\mathrm{pH} 7.4,200 \mu \mathrm{L} /$ well) for $90 \mathrm{~min}$ while shaking, the plates were then incubated with sera (1:200 dilution in $1.5 \%$ BSA in PBS, pH 7.4, $100 \mu \mathrm{L} /$ well) for $60 \mathrm{~min}$, shaking. On each plate a secondary antibody control (only serum dilution buffer) was present. Plates were washed four times with washing buffer and incubated shaking with secondary antibody (P021402-02, Dako Agilent Pathology Solutions, Santa Clara, USA, diluted 1:5000 in 5\% non-fat dried milk in PBS, pH 7.4, 100 $\mu \mathrm{L} /$ well) for $45 \mathrm{~min}$. Afterwards, the plates were washed five times with washing buffer. Then, they were incubated with $3.3^{\prime}, 5.5^{\prime}$-Tetramethylbenzidin (TMB, Seramun, Heidesee, Germany) for 5 min (100 $\mu \mathrm{L} /$ well $)$ and stopped with $0.5 \mathrm{M} \mathrm{H}_{2} \mathrm{SO}_{4}(100 \mu \mathrm{L} /$ well). The resulting colour reaction (from blue to yellow) was quantified with a SpectraFluor reader (Tecan; Maennedorf, Switzerland) at $450 \mathrm{~nm}$ and 620 $\mathrm{nm}$ as reference.

Each sample was quantified as mean of triplicate measurements. The difference between antigen mean value and sample background mean value, each corrected using mean value of the secondary antibody control, resulted in the net values which were used for evaluation according to the antigen-specific cutoff. The cutoff values (dotted lines) were determined by ROC analysis (GraphPad Software, version 8.0.0, San Diego, California USA, www.graphpad.com) versus other diseases (except SLE) or healthy controls with $98 \%$ specificity each. This threshold served for qualitative (positive/ negative) assessment of patient sera. These calculations were used for all ELISA analyses in human and mice.

The "Ratio mean OD positive" (Table 2) reflects the level of the positive signals in each mouse model and was calculated as the quotient of the mean value of the positive signals and the diagnostic cutoff.

To determine serum-reactivity against the citrullinated forms of the antigens by ELISA, the coated antigens were citrullinated in vitro by incubating for $3 \mathrm{~h}$ at $55^{\circ} \mathrm{C}$ with $60 \mathrm{mU}$ per well rabbit PAD (Sigma; St. Louis, USA) in $100 \mathrm{mM}$ Tris, $5 \mathrm{mM} \mathrm{DTT}$, and $10 \mathrm{mM} \mathrm{CaCl}_{2}$, while the control wells were incubated only with citrullination buffer. Afterwards, ELISA-experiments were carried out as described above

For detection of rheumatoid factor and reactivity against cyclic citrullinated peptides ( $\alpha$-CCP-2) commercial ELISA kits (Euroimmun, Lübeck, Germany) were applied according to the manufacturer's protocol.

To ensure reproducibility between assays, all tests were performed with the same lot of antigen, enzyme, and TMB substrate. A cit-DL/DL-positive control serum was diluted analogously to the samples and carried with each assay. Furthermore, a secondary antibody control was included with each test, where the serum dilution buffer was incubated to allow detection of the nonspecific secondary antibody background signal. The positive control and the secondary antibody control had to be within the valid range $( \pm 10 \%)$ to assure that the measurement is correct.

\section{Statistical analysis}

For statistical analysis Mann-Whitney test, Spearman correlation test or ROC calculation were performed (GraphPad Software, version 8.0.0, San Diego, CA, USA, www.graphpad.com). 


\section{Immunoaffinity purification of antibodies}

Autoantibodies to hnRNP-DL (amino acid 81-420) and hnRNP-D isoform p45 were affinity-purified from 10 RA patients by ELISA-elution technique. Antigen preparation was performed as described in the section "Enzyme-linked immunosorbent assay (ELISA)". The blocked plates were incubated overnight at $4{ }^{\circ} \mathrm{C}$ with sera diluted 1:25 in PBS with 1.5\% BSA, pH 7.4. Elution of antigen-bound antibodies was performed by incubation and shaking in $0.2 \mathrm{M}$ Glycin- $\mathrm{HCl} \mathrm{pH} 2.4$ for 10 min. The eluate was neutralized with 1:7 elution volume $1 \mathrm{M}$ Tris, $\mathrm{pH}$ 8.8, and immediately dialyzed against PBS, $\mathrm{pH}$ 7.4.

\section{Indirect immunofluorescence microscopy}

Commercial HEp-2 cell slides (ANA HEp-2 plus; Generic Assays, Dahlewitz, Germany) were used for immunofluorescence analysis. Slides were incubated with affinity-purified $\alpha$ AUF1 p45 and $\alpha$-hnRNP-DL antibodies (undiluted in PBS) or rabbit $\alpha-R C K / p 54$ [37] antibodies (1:500; University of Florida, Gainesville, Florida, USA) overnight at $4{ }^{\circ} \mathrm{C}$ in a moist chamber. After washing, slides were incubated with $\alpha$ human IgG-FITC antibody (ANA HEp-2 plus; Generic Assays, Dahlewitz, Germany) or polyclonal goat $\alpha$-rabbit IgG (H+L)-Cy3 (1:50, 111-165-144, Dianova; Hamburg, Germany) antibodies.

HeLa cells were plated and exposed $1 \mathrm{~h}$ to $0.5 \mathrm{M}$ sodium arsenite [38] and afterwards incubated with the respective primary antibodies (affinity-purified $\alpha$-hnRNPDL antibody, undiluted in PBS; rabbit $\alpha$-human AUF1 peptide antibody [19], 1:1000; mouse $\alpha$-ATXN2 antibody [39], 1:200; mouse $\alpha$-hnRNP-A2/B1, 1:500; Acris Antibodies, San Diego, USA). For immunofluorescence analysis, corresponding FITC- and Cy3-coupled, secondary antibodies were used as previously described [40].

Preparations were analysed at 400-fold magnification with a LSM510 fluorescence microscope (Carl Zeiss; Jena, Germany) fitted with the appropriate filter sets for FITC and Cy3.

\section{Immunohistochemical analysis}

We analysed an $\alpha$-hnRNP-DL antibody (ARP4085_T100; Aviva Systems Biology; San Diego, USA) in 1:50 dilution on a tissue microarray (TMA, Provitro, Berlin, Germany) with paraffin sections of human synovial tissue from patients with rheumatoid arthritis $(n=10)$, osteoarthritis $(n=12)$ and from healthy donors $(n=4)$. Immunostaining of the antibody was performed according to the manufacturer's protocol. For visualization, the Novolink ${ }^{\mathrm{Tm}}$ Polymer Detection System (RE-7140-CE; Leica Biosystems, Nussloch, Germany) was used. Slides were analysed with a CX41 microscope (Olympus, Tokyo, Japan).

\section{Preparation of synovial tissue}

Synovial tissue was collected from a patient with rheumatoid arthritis (joint biopsies, Department of Rheumatology and Clinical Immunology, Charité, Berlin). Lysis of synovial tissue was performed in M-PER Mammalian Protein Extraction Reagent. (78501; Thermo Fisher Scientific Inc., Rockford, IL, USA) with protease inhibitor cocktail (P8340; Sigma, St. Luis, USA), $100 \mu \mathrm{M}$ $\mathrm{Na} 3 \mathrm{VO} 4,150 \mathrm{mM} \mathrm{NaCl}$, and $1 \mathrm{mM}$ DTT, followed by mechanical homogenization with an Ultra Turrax (T25; IKA, Staufen, Germany) three times for $1 \mathrm{~min}$. After centrifugation $(1 \mathrm{~min}, 17,000 \times g)$ the supernatant was collected. To enhance solubility of proteins, the pellet was homogenized three times for 1 min with ultrasound (VibraCell; Sonics and Materials, Danbury, USA) in $8 \mathrm{M}$ urea. Ten microgrammes of each, the supernatant and the pellet homogenate, were separated together in one lane on a SDS-gel and transferred on a nitrocellulose membrane.

\section{Gel electrophoresis, immunoblotting and immune detection}

Total protein was measured using the Bradford assay (Roth, Karlsruhe, Germany). Equal amounts of protein in sample buffer [41] were separated on $12.5 \%$ SDS minigels with $4 \%$ stacking gel in SDS running buffer (25 $\mathrm{mM}$ Tris, $0.2 \mathrm{M}$ Glycine, $0.1 \%$ (w/v) SDS) for $40-50 \mathrm{~min}$ at $25 \mathrm{~mA}$ in a gel apparatus (Mighty Small II, Amersham Pharmacia, Uppsala, Sweden). Afterwards, proteins were transferred to nitrocellulose membranes (BA85; Schleicher \& Schuell, Dassel, Germany) using a tank blot system (TE22; Hoefer, Holliston, USA) with tankblot buffer (15 mM Tris, $0.1 \mathrm{mM}$ glycine) for $1 \mathrm{~h}$ and $400 \mathrm{~mA}$ with stirring and water cooling. After protein transfer, the Western blot was blocked for $1 \mathrm{~h}$ in blocking solution $(3 \% \mathrm{w} / \mathrm{v}$ non-fat dried milk in PBS, $\mathrm{pH} 7.4)$ and incubated with an $\alpha$-hnRNP-DL antibody (ARP40586_P050; 1:500; Aviva Systems Biology, San Diego, USA), hnRNPDL-specific rabbit antibody serum (peptide motif MEDMNEYSNIEEFAEGSK, contained in all hnRNP-DL isoforms, 1:100, Thermo Fisher Scientific, Rockford, USA) or an $\alpha$-deiminated arginine antibody (ABAP Kit; 1:500; Modiquest, Oss, Netherlands) diluted in blocking solution overnight at $4{ }^{\circ} \mathrm{C}$. After washing three times for 10 min with washing buffer (PBS, pH 7.4, 0.05\% Triton $\mathrm{X}-100)$ the blot was incubated for $1 \mathrm{~h}$ with secondary antibody (rabbit or mouse horse radish peroxidase conjugate, Dako Agilent Pathology Solutions, Santa Clara, USA) 1:1000 diluted in 3\% w/v non-fat dried milk in washing buffer. After washing five times for 5 min with washing buffer, chemiluminescence detection was performed with Roti Lumin substrate (Roth, Karlsruhe, Germany) according to the manufacturer's instructions. 


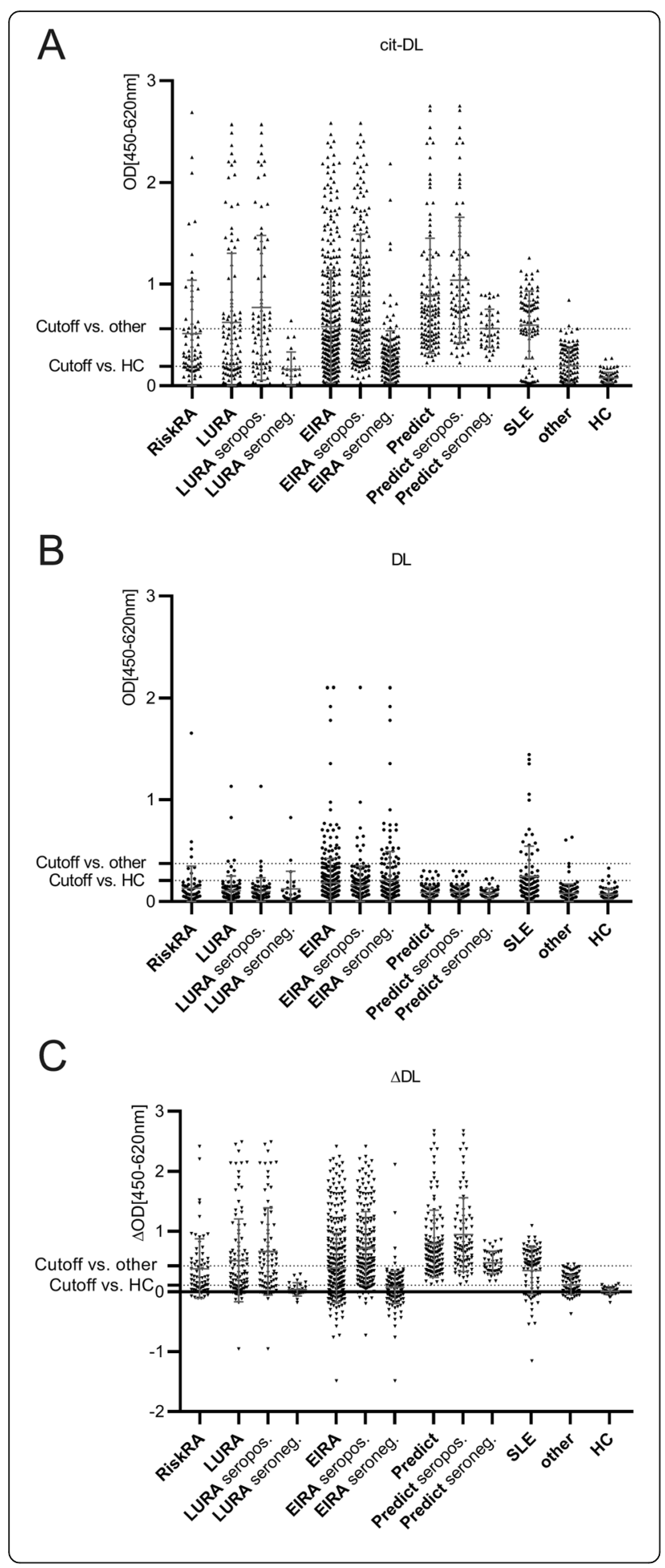

Fig. 1 Distribution of ELISA signals of a-hnRNP-DLmir autoantibodies. Reactivities were predominantly found in SLE and RA. Prevalence of citrullinated a-hnRNP-DL $L_{\text {mir }}$ (cit-DL) (A), a-hnRNP-DL mir (DL) (B) and the difference between cit-DL and $D L$ signal $(\Delta \mathrm{DL})(\mathbf{C})$ in sera from Risk-RA patients $(n=71)$, early RA patients (LURA $n=106$; EIRA $n=$ 404), established RA patients (predict $n=127)$, SLE patients ( $n=89$ ), other diseases $(n=127)$ and healthy controls $(n=86)$ determined by ELISA. The dotted lines mark the cutoff versus other diseases (except SLE) or healthy controls with $98 \%$ specificity each. OD, optical density; SLE, systemic lupus erythematosus

\section{Global sequence alignment}

With the help of the program "Needle", version 2019 [42], which can be accessed online via the EMBOSS website [43] (http://www.ebi.ac.uk/Tools/psa/emboss_ needle/; retrieved on 04 April 2020), we performed a global sequence alignment by Needleman-Wunsch algorithm [44]. The amino acid sequences of the two hnRNP proteins hnRNP-D (isoform A, $355 \mathrm{AA}$ ) and hnRNP-DL (isoform 1, 420 AA) were analysed for homologous sequence regions.

\section{Results}

Protein macroarray screening identifies the hnRNP-DL protein as a novel autoantigen targeted in rheumatoid arthritis (RA)

Sera from 26 RA patients and 40 control subjects, including osteoarthritis $(\mathrm{OA})$ patients $(n=20)$ and selfreported healthy blood donors $(n=20)$, were analysed on protein macroarrays [36]. The 20 most sensitive autoantigens only found in the RA group are listed in the Additional file 2.

We identified $\alpha$-hnRNP-DL with second highest intensity score. HnRNP-A2/B1 and hnRNP-D (AUF1) have already been described as autoantibody targets in RA $[11,19]$. Structure of hnRNP-DL and sequence alignment with hnRNP-D is shown in Additional file 1: supplementary Figure 1. One of two different hnRNP-DL clones, expressing the protein fragment from amino acid 81 to 420 , revealed autoantibody reactivity in $20 \%$ of RA sera (Additional file 2). This hnRNP-DL fragment was termed hnRNP-DL ${ }_{\text {mir }}$ (major immunogenic region). Isoform hnRNP-DL2 (amino acid 120-420) could not be detected by RA sera.

Autoantibodies against native and citrullinated hnRNP-DL are predominantly present in sera of systemic lupus erythematosus (SLE) and RA patients

To verify the results from protein macroarray screening, hnRNP-DL mir $_{\text {was }}$ expressed in E. coli BL21(DE3)pLysS, purified and tested for reactivity in ELISA as native (DL) and citrullinated protein version (cit-DL), using 1010 sera obtained from Risk-RA cohort $(n=71)$, from early RA cohorts (LURA $n=106$; EIRA $n=404$ ), from an established RA cohort (predict $n=127$ ), control cohorts 

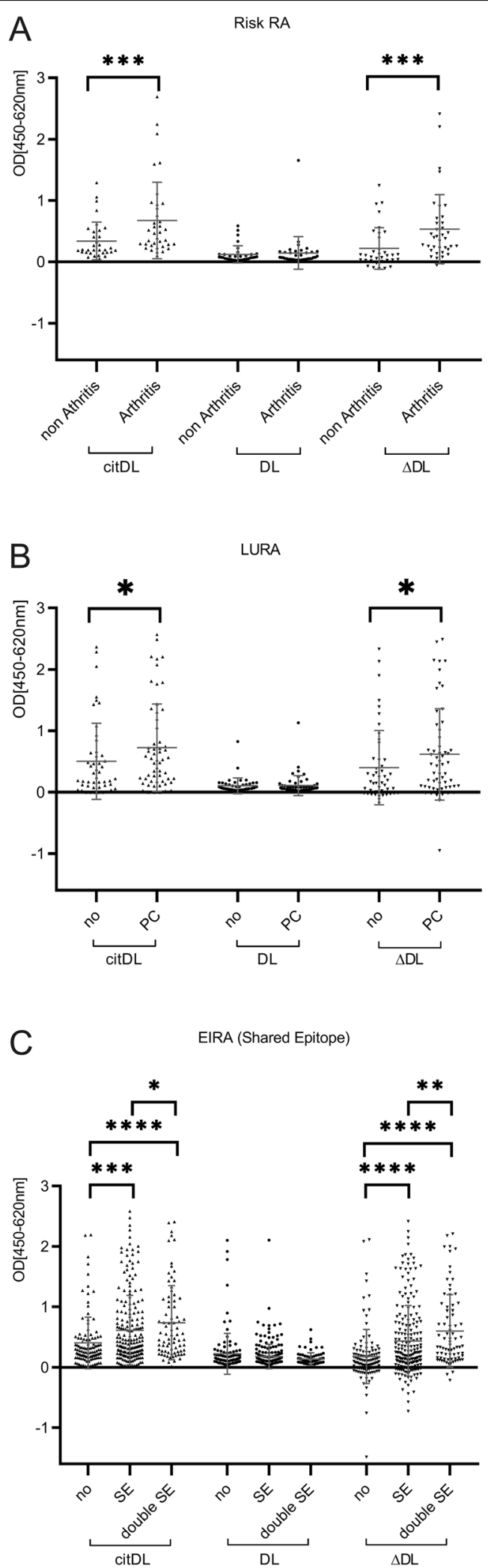

Fig. 2 Anti-citrullinated $h n R N P-D L_{\text {mir }}$ autoantibodies are detectable even before the onset and in early status of disease. A-C Anticitrullinated hnRNP-DL $L_{\text {mir }}$ (cit-DL), a-hnRNP-DL $L_{\text {mir }}(D L)$ and $\triangle O D$ between cit-DL and $D L(\Delta D L)$ were measured by ELISA. $\mathbf{A}$ In Riskpatients of arthritis the OD levels of cit-DL and $\triangle D L$ before onset are significantly specific in the patient group where the arthritis has already been diagnosed compared to the group without diagnosis ( $n=71$; non-arthritis $n=34$ /arthritis $n=37$; Mann-Whitney U; cit-DL median $_{\text {non Arthritis }}=0.19 /$ median $_{\text {Arthritis }}=0.46 ; p=0.0006 ;$ NC-index median $_{\text {non Arthritis }}=0.10 /$ median $_{\text {Arthritis }}=0.38 ; p=0.0003$ ). B, C Cit$\mathrm{DL}$ and $\Delta \mathrm{DL}$ are significantly associated with parenchymal changes in the lung of early RA patients of the LURA cohort ( $\mathbf{B} ; n=106$; no $n$ $=48 / P C n=58 ;$ Mann-Whitney U; cit-DL median $_{n o}=0.23 /$ median $_{P C}$ $=0.53 ; p=0.0340 ;$ NC-index median $_{\mathrm{no}}=0.16 /$ median $_{\mathrm{PC}}=0.44 ; p=$ 0.0332) and with and shared epitopes of the early RA patients of the EIRA cohort $(\mathbf{C} ; n=404$; no $n=112 /$ SE $n=213$ /double SE $n=79$; Mann-Whitney U; cit-DL median $_{\mathrm{no}}=0.27 /$ median $_{\mathrm{SE}}=0.36 ; p=$ 0.0003, median $_{\mathrm{no}}=0.27 /$ median $_{\text {double }} \mathrm{SE}=0.54 ; p<0.0001$, median $_{\mathrm{SE}}=0.36 /$ median $_{\text {double SE }}=0.54 ; p=0.0453 ; \mathrm{NC}$-index median $_{\mathrm{no}}=0.11 /$ median $_{\mathrm{SE}}=0.21 ; p<0.0001$, median $_{\mathrm{no}}=0.11 /$ median $_{\text {double } S E}=0.34 ; p<0.0001$, median $_{\mathrm{SE}}=0.21 /$ median $_{\text {double } S E}$ $=0.34 ; p=0.0061$ ). Mann-Whitney $U$ test was performed for analysing significance of indicated groups $\left({ }^{*} p<0.05,{ }^{* *} p<0.01,{ }^{* * *} p\right.$ $\left.<0.001{ }^{* * *} p<0.0001\right)$. OD, optical density; ns, not significant; PC, parenchymal changes in lung; $S E$, shared epitope

of other autoimmune diseases $(n=216)$ and from healthy controls $(n=86)$. Since citrullinated antigens, among them hnRNP-A2/B1 [18], are the most specific targets in RA, we analysed autoantibody responses against cit-DL, with the highest signalling and positivity found in the early and established RA cohorts (64$100 \%)$. With special focus on the seropositive and seronegative RA patients only $\alpha$-cit-DL signals differ significantly within all investigated RA cohorts, not $\alpha$-DL values (Fig. 1A/B; Additional file 1: supplementary Table 1 ). Although $\alpha$-cit-DL signals of seronegative patients were lower than those of seropositive patients, they were still significantly higher than in other diseases in EIRA and predict cohort (Additional file 1: supplementary Table 2).

The majority of $\alpha$-DL was found in sera of patients with SLE (34\%) and RA (6-21\%) and in patients with psoriasis arthritis (15\%), patients with MS (5\%) and scleroderma (5\%) as well as healthy controls (2\%) (Fig. 1B; Additional file 1: supplementary Figure 2). Interestingly, we obtained very different sensitivities within the four investigated RA cohorts whereby Risk-RA- (13\%) and EIRA cohort (21\%) showed the highest sensitivities. Cohorts under certain therapy or advanced disease duration showed lower values (LURA 8\%/predict 6\%).

Noticeable $58 \%$ of the SLE patients, using the cutoff level versus other diseases, were $\alpha$-cit-DL positive ( $\alpha$-DL $18 \%$ ), although $98 \%$ of the tested SLE sera were $\alpha$-CCP2-negative. We determined the difference between the ELISA signals, to get a value that describes the relationship between $\alpha$-cit-DL and $\alpha$-DL. This value we named 
$\mathrm{CN}_{\mathrm{DL}}$-Index $(\triangle \mathrm{DL})$, shown in Fig. $1 \mathrm{C}$, with the highest values detected in the RA cohorts. In established RA (predict), the highest $\mathrm{CN}_{\mathrm{DL}}$-Index (sensitivity, 100\%/72\% versus healthy controls/other diseases) and exclusively positive values were detected. In contrast, $11-20 \%$ of early RA patients (Risk-RA/EIRA/ LURA) had a negative $\mathrm{CN}_{\mathrm{DL}}$-index, where $\alpha$-DL was higher than $\alpha$-cit-DL. Besides, only SLE patients and single exceptions in other diseases had a negative $\mathrm{CN}_{\mathrm{DL}}$-index below - 0.1. In the early RA cohort EIRA, the $\mathrm{CN}_{\mathrm{DL}}$-Index correlated positively to $\alpha$-cit-DL and there, exclusively in the seronegative EIRA negatively to $\alpha-\mathrm{DL}$ response (Additional file 1: supplementary Figure 3).

\section{Anti-cit-DL and $\mathrm{CN}_{\mathrm{DL}}$-Index correlated with parenchymal changes in lung/shared epitope and identified people at risk to develop RA}

Anti-DL autoantibodies were detectable in early RA. Therefore, we investigated $\alpha$-CCP2-positive healthy subjects with musculoskeletal symptoms, classified as RiskRA cohort, differentiating between subjects developing arthritis during follow-up and those remaining healthy without arthritis diagnosis. Further, we analysed $\alpha$-DL autoantibody association with certain risk factors for RA. We plotted respectively $\alpha$-cit-DL, $\alpha$-DL and the $\mathrm{CN}_{\mathrm{DL}^{-}}$ index in the LURA cohort with the parenchymal changes in the lung and in the EIRA cohort with the genetic risk factor shared epitope.

In the Risk-RA cohort, $\alpha$-cit-DL and $\mathrm{CN}_{\mathrm{DL}}$-Index were significantly elevated in progressors (Fig. 2A), in the LURA cohort in patients with parenchymal lung changes (Fig. 2B) and in the EIRA in patients with shared epitope, particularly in those carrying two copies (Fig. 2C). No significant differences were found for $\alpha$-DL antibodies.

\section{High a-DL autoantibody levels found in 6-month EULAR} responders for methotrexate (MTX) or Enbrel ${ }^{\circledR}$ treatment We examined our biomarkers ( $\alpha$-cit-DL, $\alpha$-DL and $\mathrm{CN}_{\mathrm{DL}}$-index) with therapy data of the EIRA and predict cohort. One hundred and ninety-two MTX-treated EIRA patients were analysed (Fig. 3A-C; Additional file 1: supplementary Figure 4A/B). The ROC analysis of $\alpha$-DL signals reached $12 \%$ sensitivity with $90 \%$ specificity, using the RA-specific cutoff level (OD 0.371) for detecting MTX response. ROC results got more significance for detecting MTX responses in the seronegative group (cutoff $0.371 ; 16 \%$ sensitivity, 94\% specificity; Additional file 1: supplementary Table 6).

Because $\alpha$-DL correlated negatively to the $\mathrm{CN}_{\mathrm{DL}}$-Index in the seronegative group (Additional file 1: supplementary Figure 3), we analysed MTX-treated EIRA patients with negative $\mathrm{CN}_{\mathrm{DL}}$-index. Eighty-seven percent of these patients were responders. We reached sensitivities in a range of $15-33 \%$ (100/75\% specificity) to detect MTX response (Additional file 1: supplementary Table 7).

In the predict cohort (Enbrel--treatment) no $\mathrm{CN}_{\mathrm{DL}^{-}}{ }^{-}$ index/response association were found since all patients had equally high positive $\mathrm{CN}_{\mathrm{DL}}$-index and none of them negative values. ROC analysis of $\alpha$-cit-DL or $\mathrm{CN}_{\mathrm{DL}^{-}}$ index showed no specific response cutoff. But with $\alpha$ DL, we identified 23\% of the EIRA patients as MTX responder and in the seronegative group 25\% (90\% specificity). Among the established RA cohort (predict), $\alpha-D L$ reached $13 \%$ sensitivity and even $25 \%$ within the seronegative group for the detection of Enbrel $^{\circ}$ response (100\% specificity; Fig. 3D-F; Additional file 1: supplementary Table 8 ).

\section{Anti-cit-DL and $a-D L$ increase the serodiagnostic sensitivity in early RA}

All RA cohorts were analysed to determine diagnostic sensitivities of $\alpha$-cit-DL and $\alpha$-DL, in RF IgM/ $\alpha-C C P-2-$ seropositive and -negative patients.

The calculated cutoff level versus healthy controls ( $96 \%$ specificity), identified $80 \%$ of the subjects in the Risk-RA cohort, which are exclusively $\alpha$-CCP-2-positive. In the LURA/EIRA cohort $32 / 73 \%$ of the seronegative patients were identified. In the predict cohort, all patients could be identified with one of our biomarkers and $\alpha$-DL response was on average the lowest $(6 \%)$. In SLE patients, $84 \%$ in total were detected ( $\alpha$-DL, 34\%; $\alpha$ cit-DL, $80 \%)$. In other autoimmune diseases, about half $(48 \%)$ of the patients were detected in total with our biomarker set.

Using the cutoff level versus other diseases (96\% specificity), we detected $51 \%$ of the seronegative established RA patients and $8-17 \%$ of the early RA patients (Table 1 ).

\section{Localization and expression of hnRNP-DL in different cell lines and synovial tissue}

Affinity-purified $\alpha$-DL autoantibodies from RA patient sera were used for localization of hnRNP-DL in HeLaand HEp-2 cells. Sparing the nucleoli in interphase cells, staining with the $\alpha$-DL autoantibodies showed a nucleoplasmic staining with large speckles (Fig. 4A; a, b). However, the nucleoplasmic staining produced by $\alpha-h n R N P-$ $\mathrm{D}(\alpha$-AUF- 1$)$ and $\alpha$-hnRNP-A2/B1 antibodies was more homogeneous (Fig. 4A; e, f) and stained as well as $\alpha$-DL autoantibodies discrete cytoplasmic foci when cells were stressed by arsenite (Fig. 4A; c, e, f). Notably, the colocalization experiment showed $\alpha$-DL antibodies stained a subset of cytoplasmic stress granules (Fig. 4A; c), independent of size and localization. HnRNP-D could be detected in nearly all granules (Fig. 4A; g, yellow), like the controls Ataxin2 and RCK/p54 (Fig. 4A; d/h).

Since previous studies demonstrated hnRNP-A2/B1 and hnRNP-D to be highly expressed in synovial tissue 

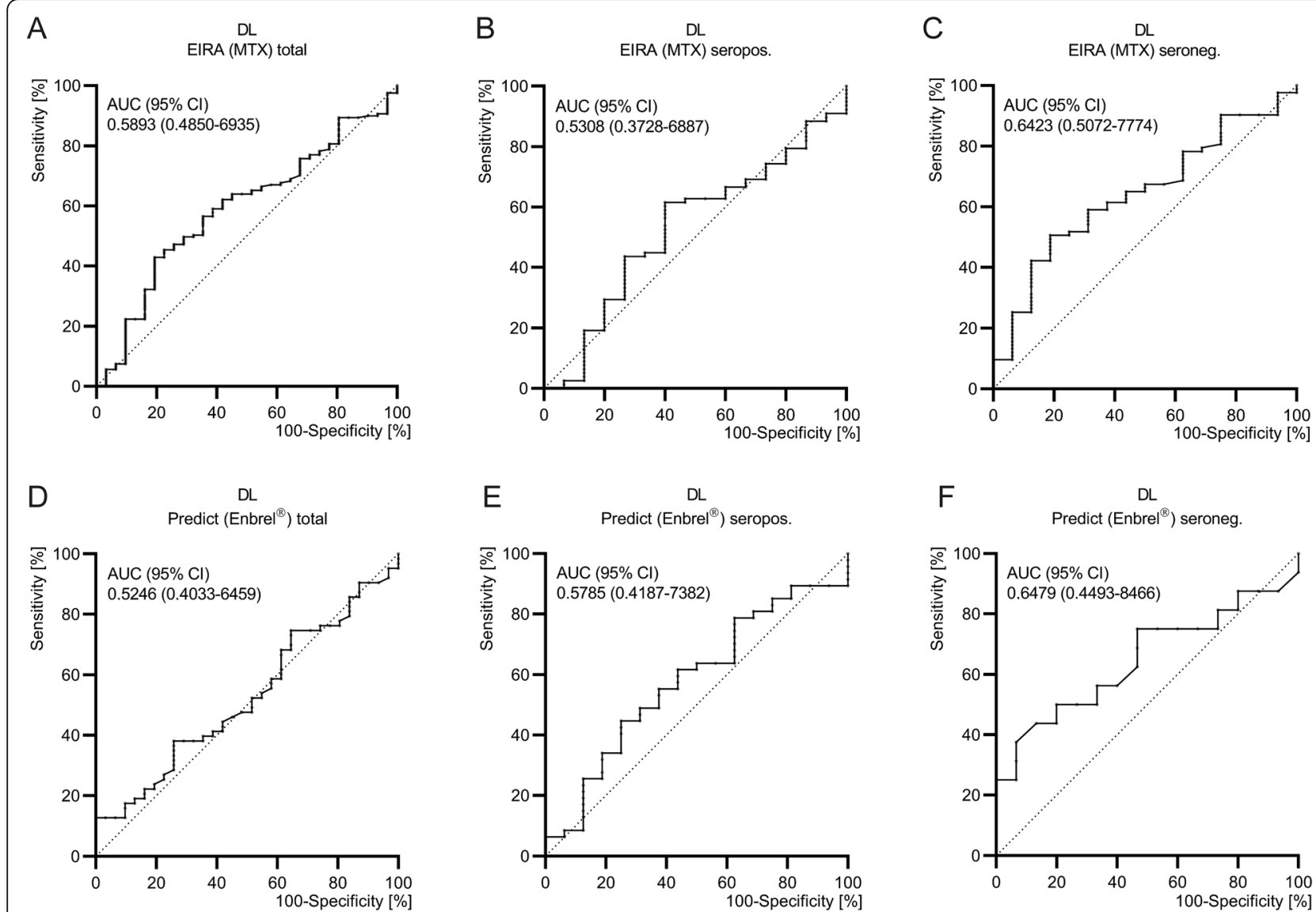

F

$\mathrm{DL}$ Predict $\left(\left.E^{-n b r e}\right|^{\oplus}\right)$ seroneg.

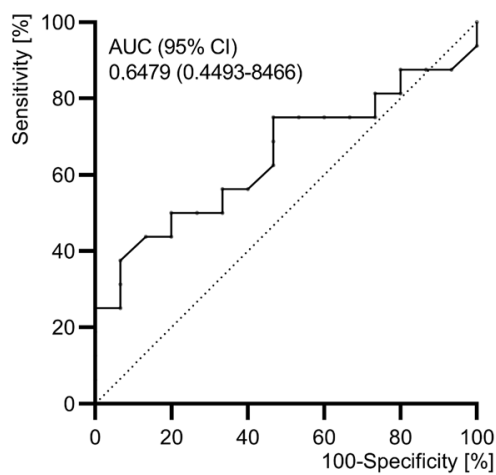

Fig. 3 Diagnostic performance of a-hnRNP-DLmir $(D L)$ for the detection of therapy response. High baseline titre against a-hnRNP-DLmir $(D L)$ is rather present in 6-month EULAR Responder RA patients who had received MTX or a-TNF inhibitor therapy (Enbrel ${ }^{\oplus}$ ). A-C a-DL were measured by ELISA in patient sera from the EIRA cohort treated with MTX $(n=192)$ with 161 EULAR responder and 31 EULAR non-responder among 6 months. Above these values, ROC analyses were performed for detecting DAS28 therapy response. D-F a-DL were measured by ELISA in patient sera from the predict cohort treated with Enbre ${ }^{\oplus}$ therapy with 6-month EULAR response data $(n=94$, responder $n=63$, non-responder $n=31)$. Based on the signals, ROC analysis was performed for detecting DAS28 therapy response. OD, optical density; vs., versus; RA, rheumatoid arthritis; MTX, methotrexate; seropos., rheumatoid factor IgM and/or a-CCP-2 positive patients; seroneg., rheumatoid factor IgM and a-CCP-2 negative patients

of RA patients and arthritic mice [19, 28, 45, 46], we analysed the expression of hnRNP-DL in the human joint. Specific rabbit antibodies recognizing hnRNPDL 1 and 2 expression were tested by immunohistochemistry in synovial tissue of RA and OA patients and from healthy controls (Fig. 4B). These analyses revealed hnRNP-DL to be highly expressed in RA tissue. Nuclear and cytoplasmic expression was seen in cells of RA synovial tissue, in contrast to the exclusive nuclear staining observed in $\mathrm{OA}$ and normal tissue (Fig. 4B, arrows).

We further investigated the expression of hnRNPDL under inflammatory conditions in IL1 $\alpha-$ and TNF $\alpha$-stimulated HepG2-, as well as in IL6stimulated HeLa cells by immunoblotting (supplementary Fig. 5 A/B). TNF $\alpha$ and particularly IL1 $\alpha$ upregulate, whereas IL6 downregulates the expression of hnRNP-DL and furthermore induces its degradation.
We further detected citrullinated proteins of the same molecular weight as of hnRNP-DL (supplementary Fig. 5 $B$ ) in the synovial tissue. The molecular weights of the detected DL bands in supplementary Figure $5 \mathrm{~B}$ do not correspond to the isoforms in supplementary Figure 5A; they may be other DL isoforms that have not been studied in detail.

\section{Anti-DL in animal models of RA and SLE with association to TLR7/9 and MyD88 - supports reference to clinical pain}

Anti-cit-DL/ $\alpha$-DL autoantibodies, in baseline samples, are associated with pain VAS after 6 months of various treatments of EIRA patients (Additional file 1: supplementary Table 3-5).

Therefore, we wanted to study the production of $\alpha$-DL autoantibodies in the context of TLR and MyD88knock-out mice, known to be involved in pain pathway 
Table 1 Sensitivity of a-citrullinated hnRNP-DL ${ }_{\text {mir }}$ (cit-DL), a-hnRNP-DL $L_{\text {mir }}(\mathrm{DL}$ ) autoantibodies and $\Delta$ OD between cit-DL and DL $(\Delta \mathrm{DL})$ in sera from Risk-RA patients, early RA patients (LURA/ EIRA), established RA patients (predict), SLE patients ( $n=89$ ), other diseases and healthy controls determined by ELISA. Sensitivities are expressed as percentages, with a $98 \%$ specificity, and were calculated using two cutoffs in each case, first, against healthy controls (to the left of the slash) and second, against other diseases except SLE (to the right of the slash). Total DL is the combined antibody reactivity and describes the proportion of patients that one detects positive overall with the combination of all three biomarkers a-cit-DL, $\mathrm{a}$-DL and/or $\triangle \mathrm{DL}$

\begin{tabular}{|c|c|c|c|c|c|c|c|c|c|c|c|c|}
\hline & \multirow[t]{2}{*}{ cit-DL } & \multirow[t]{2}{*}{$\mathrm{DL}$} & \multirow[t]{2}{*}{$\Delta \mathrm{DL}$} & \multirow{2}{*}{$\begin{array}{l}\text { total } \\
\mathrm{DL}\end{array}$} & \multicolumn{4}{|c|}{$\mathrm{RF}$ and/or CCP positive } & \multicolumn{4}{|c|}{ RF and CCP negative } \\
\hline & & & & & cit-DL & $\mathrm{DL}$ & $\Delta \mathrm{DL}$ & total DL & cit-DL & $\mathrm{DL}$ & $\Delta \mathrm{DL}$ & total DL \\
\hline Risk-RA & $n=71$ & & & & $n=71$ & & & & $n=0$ & & & \\
\hline$\%$ pos. & $70 / 28$ & $13 / 6$ & $68 / 34$ & $80 / 39$ & $70 / 28$ & $13 / 6$ & $68 / 34$ & $80 / 39$ & - & - & - & - \\
\hline LURA & $n=106$ & & & & $n=81$ & & & & $n=25$ & & & \\
\hline$\%$ pos. & $64 / 38$ & $8 / 4$ & $64 / 40$ & $69 / 42$ & $77 / 48$ & $7 / 2$ & $77 / 52$ & $80 / 53$ & $24 / 4$ & $12 / 8$ & $24 / 0$ & $32 / 8$ \\
\hline EIRA & $n=404$ & & & & $n=202$ & & & & $n=202$ & & & \\
\hline$\%$ pos. & $80 / 33$ & $21 / 9$ & $68 / 31$ & $84 / 40$ & $94 / 59$ & $17 / 5$ & $89 / 59$ & $96 / 63$ & $65 / 7$ & $25 / 14$ & $46 / 2$ & $73 / 17$ \\
\hline Predict & $n=127$ & & & & $n=86$ & & & & $n=41$ & & & \\
\hline$\%$ pos. & $100 / 67$ & $6 / 0$ & $100 / 72$ & $100 / 72$ & 100/77 & $6 / 0$ & $100 / 83$ & $100 / 83$ & $100 / 46$ & $5 / 0$ & $100 / 51$ & $100 / 51$ \\
\hline SLE & $n=89$ & & & & & & & & & & & \\
\hline$\%$ pos. & $80 / 58$ & $34 / 18$ & $72 / 57$ & $84 / 73$ & & & & & & & & \\
\hline other & $n=127$ & & & & & & & & & & & \\
\hline$\%$ pos. & $45 / 2$ & $4 / 2$ & $41 / 2$ & $48 / 4$ & & & & & & & & \\
\hline $\mathrm{HC}$ & $n=86$ & & & & & & & & & & & \\
\hline \% pos. & $2 / 0$ & $2 / 0$ & $2 / 0$ & $5 / 0$ & & & & & & & & \\
\hline
\end{tabular}

$H C$ healthy controls, RA rheumatoid arthritis, SLE systemic lupus erythematosus

$[47,48]$. Because hnRNP-DL is highly conserved in human and mouse (similarity 98.5\% [44]), we analysed $\alpha$ DL in sera of mouse models of RA and SLE (Table 2).

In zymosan-treated SKG-mice [49], $\alpha$-DL autoantibodies were twice as frequent (50\%) compared to the less severe arthritis model without zymosan induction (25\%).

Interestingly, in the interleukin-1 receptor antagonistdeficient (IL-1Ra ${ }^{-1}$ )-mouse arthritis model we found high signals of $\alpha$-DL autoantibodies in all mice tested.

MRL/lpr-mice produce antibodies against hnRNPs [50] and snRNPs [51] $\alpha$-DL autoantibodies were detectable in $85 \%$, while none of them were positive for the citrullinated protein version.

We analysed sera from TLR7-, TLR9-, and TLR7/TLR9double deficient lupus-prone MRL/lpr-mice. This investigation revealed that $\alpha$-DL autoantibodies were TLR7/-9 dependent and only completely absent in the double deficient mice, while they remained detectable in about $50 \%$ of the single TLR7- or TLR9-knock-out MRL/lpr-mice. MyD88 plays a central role in TLR-pathway [52]. We tested MyD88-deficient mice, which did not produce $\alpha$ DL autoantibodies except two mice with very low titre. Further, we tested knock-out mice of Toll interleukin-1 receptor 8 (TIR8, SIGIRR, IL1R8), a negative regulator of TLR-IL1-receptor family signalling. Genetic inactivation of this protein, which is associated with severe autoimmunity and high autoantibody production [53], increased prevalence of $\alpha-\mathrm{DL}$ autoantibodies by $50 \%$, with a three times higher mean level of ELISA signal intensity (Table 2).

\section{Discussion}

RA antibody systems are remarkably diverse, characterized by the presence of those against native proteins as well as those containing posttranslational modifications (PTMs) [54, 55]. While current models of RA have embraced PTMs as core principles of pathogenesis $[54,56]$, $\alpha$-native protein antibodies are not adequately explained by the PTM-centric paradigm of autoantigen selection. The direct $\alpha$-citrullinated protein-antibody response may depend on the presence of permissive factors, i.e., a genetic predisposition, as has been shown for $\alpha$-cit-DL with its shared epitope (SE)-dependency and the continued production of modified antigen. Chronic bacterial infection, such caused by Aggregatibacter actinomycetemcomitans [57] or Porphyromonas gingivalis, which can citrullinate hnRNPs [58] or smoking [59,60], leading to overexpression of hnRNPs, as shown by our results with overexpression and citrullination of hnRNP-DL in RA joint.

In early RA, a serodiagnostic gap of 50-60\% [61-64] left by using RF IgM/ $\alpha$-CCP-2 assays. This is of particular importance as patients considered to be autoantibody negative may erroneously not be diagnosed as having RA due to inappropriate therapeutic measures. In recent years, novel biomarkers have been described with 

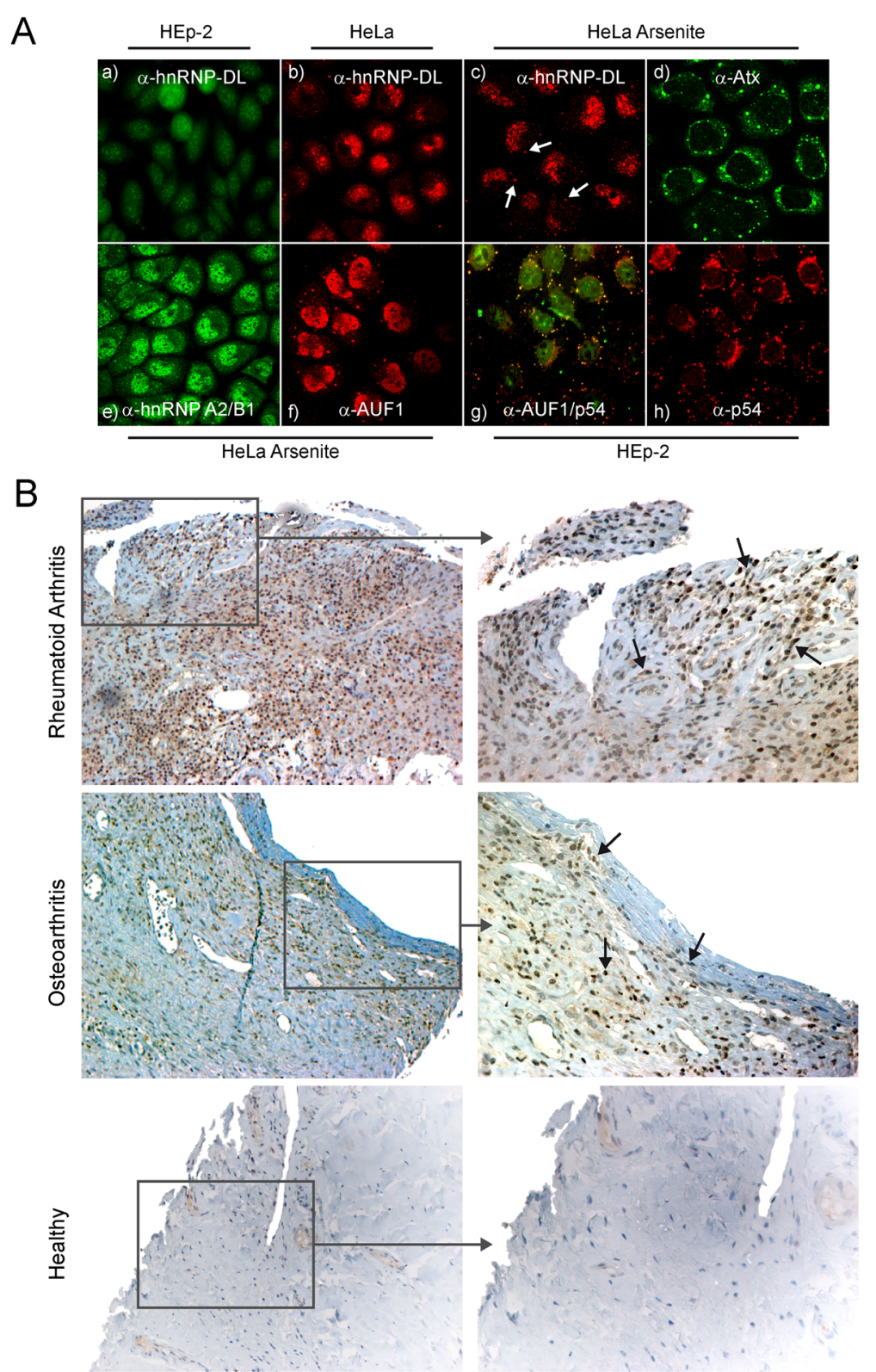

Fig. 4 Localisation and expression of cytokine-regulated, stress granule protein hnRNP-DLmir in cells, and synovial tissue. Anti-human hnRNP-DLmir antibodies detect stress granules in immunofluorescence microscopy. Staining with an affinity-purified a-human hnRNP-DLmir antibody was performed in HEp-2 (a) and HeLa cells (b). HeLa cells were treated with $0.5 \mathrm{mM}$ sodium arsenite to induce stress granules and stained with affinity-purified a-human hnRNP-DL mir antibodies (c), mouse a-human ATXN2 antibodies 63 (d), mouse a-human hnRNP-A2/B1 antibodies (e) and a-human AUF1 peptide-specific rabbit serum 19 ( $\mathrm{f}$. Co-localization of AUF1 and stress granules/P-bodies. Staining of HEp-2 cells with a-RCK/p54 64 antibodies (g) and double staining of HEp-2 cells with affinity-purified a-human AUF1 (green) and a-RCK/p54 64 antibodies (red) (h). Merged sections are visible in yellow. B Expression of hnRNP-DL in synovial tissue from a patient with rheumatoid arthritis, a patient with osteoarthritis and a healthy subject, each in 20-fold and detail in 40-fold magnification

sensitivities between 16 and $67 \%$ in $\alpha$-CCP-2-negative RA cohorts [65]. However, the clinical utility of these biomarkers is questionable because diagnostic specificities are largely unknown and will have to be shown in further studies. RF IgM/ $\alpha$-CCP-2-seronegative RA patients became seropositive by a combination of our biomarker set ( $\alpha$-cit-DL, $\alpha$-DL, $\mathrm{CN}_{\mathrm{DL}}$-index). In the clinical autoantibody testing, the new biomarker can be used for detecting people "at risk" for RA, and for early and established RA, reducing the sensitivity gap of RF IgM/ $\alpha$ CCP-2-seronegative patients (sensitivity RF IgM/ $\alpha-C C P-2$ negative LURA/EIRA/predict 32\%/73\%/100\%; Table 1). 
Table 2 Frequency of autoantibodies against recombinant $h n R N P-D L_{\text {mir }}$ in sera from different RA and SLE mouse models

\begin{tabular}{|c|c|c|c|c|c|}
\hline Mouse model & Model & Autoantigen(s) assayed & No. of sera tested & $\%$ Positive & Ratio, Mean OD positive $^{\mathrm{b}}$ \\
\hline SKG (-/+ Zymosan) & RA & $h n R N P-D L_{\text {mir }}$ & $8 / 8$ & $25 / 50$ & $2.48 / 1.23$ \\
\hline Balb/c $\left(I L-1 \operatorname{Ra}^{-/-}\right)$ & RA & hnRNP-DL $L_{\text {mir }}$ & 36 & 100 & 7.89 \\
\hline MRL-Ipr & SLE & hnRNP-DL ${ }_{\text {mir }}{ }^{a}$ & 20 & 85 & 4.22 \\
\hline MRL-Ipr (MyD88 $\left.{ }^{-/-}\right)$ & SLE & 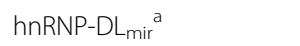 & 20 & 10 & 1.3 \\
\hline MRL-Ipr $\left(\mathrm{TLR}^{-1-}\right)$ & SLE & hnRNP-DL $L_{\text {mir }}$ & 4 & 50 & 2.42 \\
\hline MRL-Ipr $\left(T L R 7^{-/-}\right)$ & SLE & hnRNP-DL $L_{\text {mir }}$ & 7 & 43 & 2.55 \\
\hline MRL-Ipr $\left(T L R 7 / 9^{-/-}\right)$ & SLE & hnRNP-DL mir & 7 & 0 & - \\
\hline C57BL/6 Ipr & SLE & hnRNP-DL ${ }_{\text {mir }}{ }^{a}$ & 12 & 33 & 2.46 \\
\hline C57BL/6 Ipr (SIGIRR/TIR8 ${ }^{-1-}$ ) & SLE & hnRNP-DL mir ${ }^{a}$ & 12 & 83 & 6.83 \\
\hline C57BL/6 (-/+R848) & TLR7/8 agonist & hnRNP-DL $L_{\text {mir }}$ & $10 / 10$ & $0 / 10$ & $-/ 1.39$ \\
\hline
\end{tabular}

$R A$ rheumatoid arthritis, SLE systemic lupus erythematosus, SIGIRR/TIR8 Single Ig IL-1-related receptor/Toll/interleukin-1 receptor 8, R848 SIGIRR TLR7/8 agonist, MyD88 myeloid differentiation primary response gene 88 , TLR Toll-like receptor

${ }^{a}$ Additionally citrullinated $h n R N P-D L_{\text {mir }}$ were tested. In no case, citrullination of hnRNP-DL ${ }_{\text {mir }}$ resulted in a higher signal compared to the native $h n R N P-D L_{m i r}$ form (no additional reactivity)

${ }^{b}$ Ratio mean OD positive reflects the level of the positive signals in each mouse model and was calculated as the quotient of the mean value of the positive signals and the diagnostic cutoff

It has already been published that it is important to study the citrullinated signal adjusted from the unmodified protein/peptide signal, to obtain the specific signal, which is added or reduced by the modification. It has been shown that these autoantibodies occur specifically in RA, but without clinical associations such as therapy response [30, 58].

Therefore, we have introduced and tested a new biomarker $\mathrm{CN}_{\mathrm{DL}}$-index which measures the difference of $\alpha$ cit-DL and $\alpha$-DL ELISA OD levels, covering both antibodies against citrullinated epitopes and structural citrullinated epitopes (SCEs). Negative $\mathrm{CN}_{\mathrm{DL}}$-index was detectable at an early timepoint of arthritis and even before arthritis starts. Moreover, RA patients with such negative $\mathrm{CN}_{\mathrm{DL}}$-index tended to respond positively to MTX/Enbrel ${ }^{\circ}$ therapy. As RA progresses, the $\mathrm{CN}_{\mathrm{DL}^{-}}$index became increasingly positive and was associated with SE, parenchymal changes in lung and lower the response to MTX therapy.

Citrullination is a hydrolytic reaction, the target protein mobility in SDS-PAGE will shift, yielding a noncharged citrulline amino acid and neutral urea through the hydrolysis of the strongly basic positively charged side chain of arginine by water. This charge shift affects protein structure, protein-protein interactions, and hydrogen bond formation, and it may cause protein denaturation [66, 67]. This study suggests an alternative model to the PTM-centric model in which the antigen is initially targeted independent of citrullin itself, but may be depend on a structural change induced by cryptic PTM that causes the autoantibody binding. Demonstrably, the sensitivity of $\alpha$-cit-DL within the tested SLE patients was $58 \%$, almost three times higher than the sensitivity of $\alpha$-DL (18\%), calculated with the cutoff versus other diseases, although $98 \%$ of the tested SLE sera were $\alpha$-CCP-2-negative. Citrullination leads to formation of a new SCE, whose recognition is independent of directly targeting the citrulline site. This new form of $\alpha$ SCE autoantibodies may explain the shift from an initial native autoantibody response against PTMs. DNA, RNA and TLR7/9 activation are required to generate $\alpha$ hnRNP-specific B cells and this complex induced RA in a pristane-induced arthritis model of RA [68]. Interestingly, MyD88 deficiency leads to reduction of pain [47], which may explain the correlation of $\alpha$-DL with pain VAS after 6 months in the EIRA cohort. Autoantibodies against DL did not correlate to RF IgM or $\alpha-C C P-2$ or SE. These antibodies can be used specifically in the seronegative group to predict the therapeutic outcome and pain level after 6 months of treatment.

The $\alpha-\mathrm{DL}$ autoantibody level disappeared in the course of RA, inversely the $\alpha$-cit-DL autoantibody level increased, independently from the therapeutic regime. Therefore, future therapies utilizing tolerance induction may use native RA autoantigens in "high risk" individuals. Epitope spreading to PTM autoantigens can be blocked in the major mouse models of SLE and RA that we have tested, and this could be analysed experimentally with hnRNP-DL in future studies. Native antigens as part of stress granules are used in existing models of experimental arthritis to induce arthritis, but not the citrullinated antigens [68]. SE and specific exogenous factors are missing in the studied animal models of RA and SLE, explaining the lack of ACPAs and SCE autoantibodies. Anti-native protein antibodies may represent markers for the detection of risk people in the earliest pre disease of RA, preceding the development of the ACPA response, predicting a mild disease. For $\alpha$ hnRNP-A2/B1 autoantibodies, an association to less erosive disease, exclusively in early RA, has already been 
published [18, 29]. Recently, several more reactivities against native proteins in RA have been published [55]. Therefore, it is important to measure other hnRNP autoantibodies and in combination in future studies to evaluate them for personalized medicine.

\section{Conclusions}

These new data suggest that hnRNP-DL is a novel TLR7/ 9-dependent autoantigen found predominantly in RA and SLE and in mouse models of inflammatory rheumatic diseases. Our studies on hnRNP-DL have shown that citrullination can lead to structural epitopes (SCE) that can be recognized by $\alpha$-CCP-2-negative SLE patients. By using the combined assay consisting of citrullinated hnRNP-DL and native hnRNP-DL, we increase the serodiagnostic sensitivity in RA patients who are negative for RF and $\alpha$ CCP-2 autoantibodies. We demonstrated that autoantibodies against hnRNP-DL have prognostic value for the differential diagnosis of RA, especially in early disease. Immunofluorescence analyses revealed that hnRNP-DL is part of stress granules that can trigger inflammatory processes in RA. Our results indicate that truncated, possibly citrullinated, immunogenic hnRNP-DL can be detected in synovial tissue.

We hypothesize that hnRNP autoantibodies generated by patients with systemic autoimmune diseases are directed against mRNA decay complexes that are part of the stress granules. We hypothesize that increased formation and structural modification of such protein complexes by bacterial or human enzymes (e.g., in inflammatory processes with overexpression of IL1 $\alpha$ and/or TNF $\alpha$ ) may lead to a pathogenic autoimmune response against a structurally altered form of native hnRNP-DL and that SCE epitopes may arise before the temporal increase in PTM-specific targets. In conclusion, the introduction of a $\mathrm{CN}$-index biomarker that measures specific anti-citrulline signalling in autoantigens will help to objectively facilitate early RA treatment decisions that are not measurable with current commercial ACPA assays.

Further autoantibody studies with additional hnRNP family proteins in native and citrullinated form should follow to identify new subsets of reactivities in RA patients. In addition, the clinical significance of the structural epitopes should be investigated in detail.

\footnotetext{
Abbreviations

AA: Amino acid; ANA HEp-2: Indirect immunofluorescence to anti-nuclear autoantibodies with fixed human epithelial cells; AREs: AU-rich elements; ATXN: Ataxin-2; IL-1Ra: Interleukin-1 receptor antagonist; AUF1: TNFa regulatory protein; BSA: Bovine serum albumin; cit-DL: Citrullinated hnRNP$D L ; C N_{D L}$-Index: Difference of ELISA signal of a-citrullinated and a-native hnRNP-DL ( $\Delta$ hnRNP-DL); DTT: Dithiothreitol; ELISA: Enzyme-linked immunosorbent assay; HAM/TSP: HTLV-1-associated myelopathy/tropical spastic paraparesis; HC: Healthy controls; HeLa: Human immortal cell line from cervical cancer taken from Henrietta Lacks; HepG2: A human liver cancer cell line; hnRNP-DL: Heterogeneous nuclear ribonucleoprotein D-like;
}

IL: Interleukin; JKTBP: JKT41-binding protein; LB medium: Lysogeny broth; MB: Ankylosing spondylitis; MCTD: Mixed connective tissue disease; mir: Major immunogenic region; MS: Multiple sclerosis; MTX: Methotrexate; MyD88: Myeloid differentiation primary response gene 88; OA: Osteoarthritis; PBS: Phosphate-buffered saline; PC: Parenchymal changes in the lung; PCR: Polymerase chain reaction; PSA: Psoriasis arthritis; PTMs: Posttranslational modifications; R848: SIGIRR TLR7/8 agonist; RA: Rheumatoid arthritis; RA33: Autoantibodies against hnRNP-A2/B1; RBD: RNA binding domains; RCK/p54: DEAD box/RNA helicase protein; ROC: Receiver operating characteristic; SCE: Structural citrullination dependent epitopes; SDSPAGE: Sodiumdodecyl sulfate-polyacrylamide electrophoresis; SE: Shared epitope; SIGIRR/TIR8: Single Ig IL-1-related receptor/ Toll/interleukin-1 receptor 8; SLE: Systemic lupus erythematosus; TBS: Tris buffered saline; TBST: Tris buffered saline-Tween; TBST-T: Tris buffered saline-Tween-TritonX; TLR: Tolllike receptor; TNF: Tumour necrosis factor

\section{Supplementary Information}

The online version contains supplementary material available at https://doi. org/10.1186/s13075-021-02603-x.

\section{Additional file 1: Figure 1. Sequence, structure and major} immunogenic region (mir) of hnRNP-D and hnRNP-DL. A, Schematic representation of hnRNP-D (isoform p45), hnRNP-DL and the different recombinant hnRNP-DL variants studied. The main structural features are highlighted. Mir-region is the major immunogenic region, RBD1 and RBD2 are RNA-binding domains 1 and 2, Gly-rich is the C-terminal glycine-rich region of the proteins. B, Global amino acid sequence alignment of hnRNP-D and hnRNP-DL1 (isoform 1). HnRNP-D and -DL share 89.1\% similarity by sequenc e[1]. Regions "mir", "RBD1", "RBD2" and "Glyrich" are highlighted. Figure 2. Characterisation of autoantibodies against, $A$, citrullinated $a-h n R N P-D L_{\text {mir }}$ (cit-DL), B, a-hnRNP-DLmir $(D L)$ and $C, \triangle O D$ between cit-DL and $D L(\triangle D L)$ determed by ELISA in sera of other diseases ( $n=127$; $M S n=20$, reA $n=7$, Sclero $n=20$, Sjö $n=20$, PsA $n=20, M B$ $n=20, O A n=20$ ). The dotted lines markes the cutoff vs. other diseases (except systemic lupus erythematosus) or healthy controls with $98 \%$ specificity each. OD, optical density; nm, nano meter; vs., versus; MS, multiple sclerosis; reA, reactive arthritis; Sclero, scleroderma; Sjö, Sjögren's syndrome; PsA, psoriasis arthritis; MB, ankylosing spondylitis; OA. Osteoarthritis. Table 1. Mann Whitney U-test of (cit) a-hnRNP-DL mir $O D$ signals of seropositive and seronegative data sets of RA-cohorts. Table 2. Mann Whitney U-test of cit a-hnRNP-DL mir-OD signals of seronegative data sets of RA-cohorts and data sets of other inflammatory diseases. Figure $\mathbf{3}$. $\mathrm{XY}$-Plot and Spearman Correlation of citrullinated or native a-hnRNP$D L_{\text {mir }}$ versus $\triangle h n R N P-D L_{\text {mir }}$ for the early RA cohort EIRA (A/D; $\left.n=404\right)$, the seropositive EIRA sera $(B / E ; n=202)$ and the seronegative EIRA sera (C/F; $n=202$ ). Table 3. Spearman correlation of the early RA sera of the EIRA cohort ( $n=404)$. The results are given as $R$ value (left of slash) with the corresponding p-value (right of slash). Table 4. Spearman correlation of the 242 EIRA sera treated with MTX (a-CCP2 positive $n=133$, a-CCP2 negative $n=109$ ). The results are given as $R$ value (left of slash) with the corresponding p-value (right of slash). Table 5. Spearman correlation of the established RA sera of the Predict cohort ( $n=94$; RF IgM and/or aCCP2 positive $n=64$, RF IgM and a-CCP2 negative $n=30$ ). The results are given as $R$ value (left of slash) with the corresponding p-value (right of slash). Table 6. ROC analysis of native hnRNP-DL mir of MTX-treated EIRA patients ( $n=192$; seropositive $n=93$, seronegative $n=99$ ). Table 7. Negative $C N_{D L}$-index of MTX-treated EIRA patients $n=192$ (Resp. $n=161$, nonResp. $n=31$ ). Table 8. $R O C$ analysis of native $h n R N P-D L_{\text {mir }}$ of Enbrel ${ }^{{ }_{-}}$ treated Predict patients ( $n=94$; seropositive $n=63$, seronegative $n=31$ ). Figure 4. High baseline titer against a-hnRNP-DL $L_{\text {mir }}(D L)$ is rather present in 6-month EULAR Responder RA patients who had received MTX or aTNF inhibitor therapy $\left(\right.$ Enbrel $\left.^{\oplus}\right)$. A-C, Citrullinated a-hnRNP-DL mir $_{\text {(citDL) }}$ (A), a-hnRNP-DL mir $(\mathrm{DL})(\mathrm{B})$ and $\triangle \mathrm{OD}$ between citDL and $\mathrm{DL}(\Delta \mathrm{DL})(\mathrm{C})$ were measured by ELISA in patient sera from the EIRA cohort treated with MTX ( $n=192$ ) with 161 EULAR Responder and 31 EULAR nonResponder among 6 months. The evaluation was done according to the cutoff versus other diseases. D, a-DL were measured by ELISA in patient sera from the Predict cohort treated with a-TNF inhibitor therapy with 6month EULAR response data ( $n=94$, responder $n=63$, non-Responder $n=$ 
31). Based on the signals, a response-cutoff (dotted line, OD 0.174) was determined, from which only responders are recognized as positive. OD, optical density; nm, nano meter; RA, rheumatoid arthritis; SLE, systemic lupus erythematosus; MTX, Methotrexate; Resp., 6-month EULAR Responder. Figure 5. A, Influence of cytokines on hnRNP-DL expression determined by immunoblotting. Cellular extracts from unstimulated, IL1aor TNFa-stimulated HeLa cells and from unstimulated and IL6-stimulated HepG2 cells were probed with a-hnRNP-DL1/2-peptide specific rabbit serum. B, Citrullination of hnRNP-DL in synovial tissue from a patient with rheumatoid arthritis was investigated with an a-deiminated arginine antibody and an a-hnRNP-DL antibody. Both positive bands were labled with hnRNP-DL, which isoforms were not analysed.

Additional file 2: Tab. 1. Antigens.

\section{Acknowledgements}

We thank Prof. Gary Brewer (Rutgers Robert Wood Johnson Medical School, Piscataway, NJ, USA) who provided the AUF1p45 clone, Prof. Edward K.L. Chan (Department of Oral Biology, University of Florida, Gainesville, USA) for providing a-RCK/p54 antibody and Dr. Stefan Bänziger (Division of Infectious Diseases and Hospital Epidemiology, University Hospital of Zurich, Zurich, Switzerland) for providing mice sera from C57BL/6 (-/+ R848).

Thanks to Prof. Gerhard Krönke from Erlangen, who provided additional sera of risk-RA.

We wish to thank EIRA study participants and the EIRA study group for their contributions, Professor Lars Klareskog for establishing the EIRA study and for support and scientific input, and Sarah Ohrendorf for comments reading the manuscript.

\section{Authors' contributions}

BM and KS conceived the study and design. BM, TH, UN, SK, APC, GS, and KS for acquisition of data. DMR, MIK, KJA, AIC, VJ, APC, MJS, and GS collected database and biological material. BM, ZK, MJ, FW, GS, KS, and JR involved in analysis and interpretation of data. All authors, BM, MJ, ZK, TH, FW, UN, SK, DMR, MIK, HJA, GRB, AIC, VJ, APC, MJS, JR, GS, and KS, were involved in drafting the article or revising it critically for important intellectual content. The authors read and approved the final manuscript.

\section{Authors' information}

AIC MD, PhD, Professor, Group Leader at Karolinska Institutet died in March 2021.

\section{Funding}

The work was supported by grants from the project ArthroMark (grant number 01EC1401A) and the project ProgRATE (KMU-innovativ-8) (grant number 0315941C) of the Federal Ministry for Education and Research (BMBF) and the IMI EU funded project BTCure (grant number 115142-2), additional KMU-innovativ: tIVDiRA FKZ 13GW0194CA with the project partner: Charité and the RTCure project. RTCure (Rheuma Tolerance for Cure) is a large, pan-European collaborative initiative funded by the Innovative Medicines Initiative (IMI). IMI is the world's biggest public-private partnership (PPP) in the life sciences. It is a partnership between the European Union and the European Federation of Pharmaceutical Industries and Associations (EFPIA). The RTCure project has received funding from the Innovative Medicines Initiative 2 Joint Undertaking under grant agreement no. 777357. Open Access funding enabled and organized by Projekt DEAL.

\section{Availability of data and materials}

Not applicable

\section{Declarations}

\section{Ethics approval and consent to participate}

The study has been performed in compliance with the Declaration of Helsinki, with informed consent obtained from all study participants, and ethical approval granted at the Regional Ethical Review Board in Berlin, Erlangen, Vienna, and Stockholm.

\section{Consent for publication}

Not applicable

\section{Competing interests}

The authors declare that they have no conflicting financial interest and have not received funding from commercial sources in the context of this study. KS and ZK are co-inventors of the patent WO/2010/072673 Diagnostic Prediction of Rheumatoid Arthritis and Systemic Lupus Erythematosus, protecting the use of the hnRNP-DL and cit-hnRNP-DL in RA and SLE.

\section{Author details}

${ }^{1}$ Department of Rheumatology and Clinical Immunology, Charité Universitätsmedizin Berlin, Charite Campus Mitte, Rheumatologisches Forschungslabor - AG Skriner, Chariteplatz 1 (intern Virchowweg 11, 5.OG, R011), 10117 Berlin, Germany. ${ }^{2}$ German Rheumatism Research Centre, Leibniz Institute, 10117 Berlin, Germany. ${ }^{3}$ Max Planck Institute for Molecular Genetics, Berlin, Germany. ${ }^{4}$ Max Planck Institute of Colloids and Interfaces, Potsdam, Germany. ${ }^{5}$ Department of Analytical Chemistry (Dpt.1), Bundesanstalt für Materialforschung und-prüfung (BAM), Berlin, Germany. 'Department of Experimental Rheumatology, Radboud University Medical Center, Nijmegen, The Netherlands. ${ }^{7}$ Division of Rheumatology, Department of Medicine Solna, Karolinska Institutet, Karolinska University Hospital, Stockholm, Sweden. ${ }^{8}$ Centre for Rheumatic Diseases, School of Immunology and Microbial Sciences, Faculty of Life Sciences and Medicine, King's College London, London, UK. 'Department of Immunology, University of Pittsburgh School of Medicine, Pittsburgh, PA, USA. ${ }^{10}$ Medical Clinic and Policlinic IV, Nephrological Center, Ludwig-Maximilian-University Hospital, Munich Germany. ${ }^{11}$ Academic Specialist Center, Center for Rheumatology, Stockholm Health Region, Stockholm, Sweden. ${ }^{12}$ Department of Immunology, Genetics and Pathology, Uppsala University, Uppsala, Sweden. ${ }^{13}$ Division of Rheumatology, Medical University of Vienna, Vienna, Austria. ${ }^{14}$ Ludwig Boltzmann Cluster for Arthritis and Rehabilitation, Vienna, Austria.

Received: 25 May 2021 Accepted: 6 August 2021

Published online: 14 September 2021

\section{References}

1. Fritzler MJ, Ali R, Tan EM. Antibodies from patients with mixed connective tissue disease react with heterogeneous nuclear ribonucleoprotein or ribonucleic acid (hnRNP/RNA) of the nuclear matrix. J Immunol. 1984;132(3): 1216-22.

2. Zouali M, Eyquem A. Antibodies to heterogeneous nuclear ribonucleoproteins in sera from patients with rheumatic autoimmune diseases. J Clin Immunol. 1984;4(3):209-19. https://doi.org/10.1007/BF00914968.

3. Dreyfuss G, Matunis MJ, Piñol-Roma S, Burd CG. hnRNP proteins and the biogenesis of mRNA. Annu Rev Biochem. 1993;62(1):289-321. https://doi. org/10.1146/annurev.bi.62.070193.001445.

4. Carson $\mathrm{JH}, \mathrm{Kwon} \mathrm{S}$, Barbarese E. RNA trafficking in myelinating cells. Curr Opin Neurobiol. 1998;8(5):607-12. https://doi.org/10.1016/S0959-43 88(98)80088-3.

5. Biamonti G, Ghigna C, Caporali R, Montecucco C. Heterogeneous nuclear ribonucleoproteins (hnRNPs): an emerging family of autoantigens in rheumatic diseases. Clin Exp Rheumatol. 1998;16(3):317-26.

6. Hoffmann MH, Skriner K, Herman S, Baumann C, Steiner CW, Ospelt C, et al. Nucleic acid-stimulated antigen-presenting cells trigger $T$ cells to induce disease in a rat transfer model of inflammatory arthritis. J Autoimmun. 2011; 36(3-4):288-300. https://doi.org/10.1016/j.jaut.2011.02.007.

7. Krecic AM, Swanson MS. hnRNP complexes: composition, structure, and function. Curr Opin Cell Biol. 1999;11(3):363-71. https://doi.org/10.1016/ S0955-0674(99)80051-9.

8. Yukitake M, Sueoka E, Sueoka-Aragane N, Sato A, Ohashi H, Yakushiji Y, et al. Significantly increased antibody response to heterogeneous nuclear ribonucleoproteins in cerebrospinal fluid of multiple sclerosis patients but not in patients with human T-lymphotropic virus type l-associated myelopathy/tropical spastic paraparesis. J Neuro-Oncol. 2008;14(2):130-5. https://doi.org/10.1080/13550280701883840

9. Sueoka E, Yukitake M, Iwanaga K, Sueoka N, Aihara T, Kuroda Y. Autoantibodies against heterogeneous nuclear ribonucleoprotein B1 in CSF of MS patients. Ann Neurol. 2004;56(6):778-86. https://doi.org/10.1002/ana.20276.

10. Siapka S, Patrinou-Georgoula M, Vachoyiannopoulos PG, Guialis A. Multiple specificities of autoantibodies against hnRNP A/B proteins in systemic rheumatic diseases and hnRNP L as an associated novel autoantigen. Autoimmunity. 2007; 40(3):223-33. https://doi.org/10.1080/08916930701352357. 
11. Steiner G, Skriner K, Smolen JS. Autoantibodies to the A/B proteins of the heterogeneous nuclear ribonucleoprotein complex: novel tools for the diagnosis of rheumatic diseases. Int Arch Allergy Immunol. 1996;111(4):3149. https://doi.org/10.1159/000237386.

12. Trembleau S, Hoffmann M, Meyer B, Nell V, Radner H, Zauner W, et al. Immunodominant T-cell epitopes of hnRNP-A2 associated with disease activity in patients with rheumatoid arthritis. Eur J Immunol. 2010;40(6): 1795-808. https://doi.org/10.1002/eji.200939482.

13. Skriner K, Sommergruber WH, Tremmel V, Fischer I, Barta A, Smolen JS, et al. Anti-A2/RA33 autoantibodies are directed to the RNA binding region of the A2 protein of the heterogeneous nuclear ribonucleoprotein complex. Differential epitope recognition in rheumatoid arthritis, systemic lupus erythematosus, and mixed connective tissue disease. J Clin Invest. 1997; 100(1):127-35. https://doi.org/10.1172/JCl1 19504.

14. Schett G, Dumortier H, Hoefler E, Muller S, Steiner G. B cell epitopes of the heterogeneous nuclear ribonucleoprotein A2: identification of a new specific antibody marker for active lupus disease. Ann Rheum Dis. 2009; 68(5):729-35. https://doi.org/10.1136/ard.2007.087502.

15. Dangli A, Plomaritoglou A, Boutou E, Vassiliadou N, Moutsopoulos HM, Guialis A. Recognition of subsets of the mammalian A/B-type core heterogeneous nuclear ribonucleoprotein polypeptides by novel autoantibodies. Biochem J. 1996;320(Pt 3):761-7. https://doi.org/10.1042/ bj3200761.

16. Skriner K, Steiner G, Sommergruber WH, Sinski A, Smolen JS. Anti-RA33 autoantibodies may recognize epitopes in the N-terminal region of hnRNPA2 (RA33). Clin Exp Rheumatol. 1994;12(Suppl 11):S79-82.

17. Hassfeld W, Steiner G, Studnicka-Benke A, Skriner K, Graninger W, Fischer I, et al. Autoimmune response to the spliceosome. An immunologic link between rheumatoid arthritis, mixed connective tissue disease, and systemic lupus erythematosus. Arthritis Rheum. 1995;38(6):777-85. https:// doi.org/10.1002/art.1780380610

18. Konig MF, Giles JT, Nigrovic PA, Andrade F. Antibodies to native and citrullinated RA33 (hnRNP A2/B1) challenge citrullination as the inciting principle underlying loss of tolerance in rheumatoid arthritis. Ann Rheum Dis. 2016;75(11):2022-8. https://doi.org/10.1136/annrheumdis-2015-208529.

19. Skriner K, Hueber W, Süleymanoglu E, Höfler E, Krenn V, Smolen J, et al. AUF1, the regulator of tumor necrosis factor alpha messenger RNA decay, is targeted by autoantibodies of patients with systemic rheumatic diseases. Arthritis Rheum. 2008;58(2):511-20. https://doi.org/10.1002/art.23306.

20. Nakielny S, Dreyfuss G. Nuclear export of proteins and RNAs. Curr Opin Cell Biol. 1997;9(3):420-9. https://doi.org/10.1016/S0955-0674(97)80016-6.

21. Guil S, Long JC, Cáceres JF. hnRNP A1 relocalization to the stress granules reflects a role in the stress response. Mol Cell Biol. 2006;26(15):5744-58. https://doi.org/10.1128/MCB.00224-06.

22. Bandiera A, Medic N, Akindahunsi AA, Manzini G. In-vitro dual binding activity of a evolutionarily related subgroup of hnRNP proteins. Mol Cell Biochem. 2005;268(1-2):121-7. https://doi.org/10.1007/s11010-005-3700-1.

23. Kamei $D$, Tsuchiya $N$, Yamazaki M, Meguro $H$, Yamada $M$. Two forms of expression and genomic structure of the human heterogeneous nuclear ribonucleoprotein D-like JKTBP gene (HNRPDL). Gene. 1999;228(1-2):13-22. https://doi.org/10.1016/S0378-1119(99)00020-7.

24. Kawamura H, Tomozoe Y, Akagi T, Kamei D, Ochiai M, Yamada M. Identification of the nucleocytoplasmic shuttling sequence of heterogeneous nuclear ribonucleoprotein D-like protein JKTBP and its interaction with mRNA. J Biol Chem. 2002;277(4):2732-9. https://doi.org/10.1 074/jbc.M108477200

25. Boopathi E, Lenka N, Prabu SK, Fang JK, Wilkinson F, Atchison M, et al. Regulation of murine cytochrome $\mathrm{c}$ oxidase $\mathrm{Vb}$ gene expression during myogenesis: YY-1 and heterogeneous nuclear ribonucleoprotein D-like protein (JKTBP1) reciprocally regulate transcription activity by physical interaction with the BERF-1/ZBP-89 factor. J Biol Chem. 2004;279(34):3524254. https://doi.org/10.1074/jbc.M403160200.

26. Reboll MR, Oumard A, Gazdag AC, Renger I, Ritter B, Schwarzer M, et al. NRF IRES activity is mediated by RNA binding protein JKTBP1 and a 14-nt RNA element. Rna. 2007;13(8):1328-40. https://doi.org/10.1261/rna.545407.

27. Doi A, Shiosaka T, Takaoka Y, Yanagisawa K, Fujita S. Molecular cloning of the cDNA encoding A + U-rich element RNA binding factor. Biochim Biophys Acta. 1998;1396(1):51-6. https://doi.org/10.1016/S0167-4781(97)00223-6.

28. Hayer S, Tohidast-Akrad M, Haralambous S, Jahn-Schmid B, Skriner K, Trembleau S, et al. Aberrant expression of the autoantigen heterogeneous nuclear ribonucleoprotein-A2 (RA33) and spontaneous formation of rheumatoid arthritis-associated anti-RA33 autoantibodies in TNF-alpha transgenic mice. J Immunol. 2005;175(12):8327-36. https://doi.org/10.4049/ jimmunol.175.12.8327.

29. Nell VP, Machold KP, Stamm TA, Eberl G, Heinzl H, Uffmann M, et al. Autoantibody profiling as early diagnostic and prognostic tool for rheumatoid arthritis. Ann Rheum Dis. 2005;64(12):1731-6. https://doi.org/1 0.1136/ard.2005.035691.

30. Rönnelid J, Hansson M, Mathsson-Alm L, Cornillet M, Reed E, Jakobsson PJ, et al. Anticitrullinated protein/peptide antibody multiplexing defines an extended group of ACPA-positive rheumatoid arthritis patients with distinct genetic and environmental determinants. Ann Rheum Dis. 2018;77(2):20311. https://doi.org/10.1136/annrheumdis-2017-211782.

31. Stolt P, Bengtsson C, Nordmark B, Lindblad S, Lundberg I, Klareskog L, et al. Quantification of the influence of cigarette smoking on rheumatoid arthritis: results from a population based case-control study, using incident cases. Ann Rheum Dis. 2003;62(9):835-41. https://doi.org/10.1136/ard.62.9.835.

32. Reynisdottir G, Karimi R, Joshua V, Olsen H, Hensvold AH, Harju A, et al. Structural changes and antibody enrichment in the lungs are early features of anti-citrullinated protein antibody-positive rheumatoid arthritis. Arthritis Rheum. 2014;66(1):31-9. https://doi.org/10.1002/art.38201.

33. Arnett FC, Edworthy SM, Bloch DA, McShane DJ, Fries JF, Cooper NS, et al. The American Rheumatism Association 1987 revised criteria for the classification of rheumatoid arthritis. Arthritis Rheum. 1988;31(3):315-24. https://doi.org/10.1002/art.1780310302.

34. Tan EM, Cohen AS, Fries JF, Masi AT, McShane DJ, Rothfield NF, et al. The 1982 revised criteria for the classification of systemic lupus erythematosus. Arthritis Rheum. 1982;25(11):1271-7. https://doi.org/10.1002/art.1780251101.

35. Alarcón-Segovia D, Cardiel MH. Comparison between 3 diagnostic criteria for mixed connective tissue disease. Study of 593 patients. J Rheumatol. 1989:16(3):328-34

36. Büssow K, Cahill D, Nietfeld W, Bancroft D, Scherzinger $E$, Lehrach $H$, et al. A method for global protein expression and antibody screening on highdensity filters of an arrayed cDNA library. Nucleic Acids Res. 1998;26(21): 5007-8. https://doi.org/10.1093/nar/26.21.5007.

37. Lian S, Fritzler MJ, Katz J, Hamazaki T, Terada N, Satoh M, et al. Small interfering RNA-mediated silencing induces target-dependent assembly of GW/P bodies. Mol Biol Cell. 2007;18(9):3375-87. https://doi.org/10.1091/mbc e07-01-0070.

38. Nonhoff U, Ralser M, Welzel F, Piccini I, Balzereit D, Yaspo ML, et al. Ataxin-2 interacts with the DEAD/H-box RNA helicase DDX6 and interferes with Pbodies and stress granules. Mol Biol Cell. 2007;18(4):1385-96. https://doi. org/10.1091/mbc.e06-12-1120.

39. Kaehler $C$, Isensee J, Nonhoff U, Terrey M, Hucho T, Lehrach $H$, et al. Ataxin2-like is a regulator of stress granules and processing bodies. PLoS One. 2012;7(11):e50134. https://doi.org/10.1371/journal.pone.0050134.

40. Welzel F, Kaehler C, Isau M, Hallen L, Lehrach H, Krobitsch S. FOX-2 dependent splicing of ataxin-2 transcript is affected by ataxin-1 overexpression. PLoS One. 2012;7(5):e37985. https://doi.org/10.1371/journal. pone.0037985.

41. Laemmli UK. Cleavage of structural proteins during the assembly of the head of bacteriophage T4. Nature. 1970;227(5259):680-5. https://doi.org/10.1 038/227680a0.

42. Madeira F, Park YM, Lee J, Buso N, Gur T, Madhusoodanan N, et al. The EMBL-EBI search and sequence analysis tools APIs in 2019. Nucleic Acids Res. 2019;47(W1):W636-W41. https://doi.org/10.1093/nar/gkz268.

43. Rice P, Longden I, Bleasby A. EMBOSS: the European Molecular Biology Open Software Suite. Trends Genet. 2000;16(6):276-7. https://doi.org/10.101 6/S0168-9525(00)02024-2.

44. Needleman SB, Wunsch CD. A general method applicable to the search for similarities in the amino acid sequence of two proteins. J Mol Biol. 1970; 48(3):443-53. https://doi.org/10.1016/0022-2836(70)90057-4.

45. Fritsch R, Eselböck D, Skriner K, Jahn-Schmid B, Scheinecker C, Bohle B, et al. Characterization of autoreactive $T$ cells to the autoantigens heterogeneous nuclear ribonucleoprotein A2 (RA33) and filaggrin in patients with rheumatoid arthritis. J Immunol. 2002;169(2):1068-76. https://doi.org/10.404 9/jimmunol.169.2.1068.

46. Schett G, Hayer S, Tohidast-Akrad M, Schmid BJ, Lang S, Türk B, et al. Adenovirus-based overexpression of tissue inhibitor of metalloproteinases 1 reduces tissue damage in the joints of tumor necrosis factor alpha transgenic mice. Arthritis Rheum. 2001;44(12):2888-98. https://doi.org/10.1 002/1529-0131(200112)44:12<2888::AID-ART477>3.0.CO;2-3. 
47. Liu F, Wang Z, Qiu Y, Wei M, Li C, Xie Y, et al. Suppression of MyD88dependent signaling alleviates neuropathic pain induced by peripheral nerve injury in the rat. J Neuroinflammation. 2017;14(1):70. https://doi.org/1 0.1186/s12974-017-0822-9.

48. Lacagnina MJ, Watkins LR, Grace PM. Toll-like receptors and their role in persistent pain. Pharmacol Ther. 2018;184:145-58. https://doi.org/10.1016/j. pharmthera.2017.10.006.

49. Kobayashi K, Suda T, Nan-Ya K, Sakaguchi N, Sakaguchi S, Miki I. Cytokine production profile of splenocytes derived from zymosan A-treated SKG mice developing arthritis. Inflamm Res. 2006;55(8):335-41. https://doi.org/1 0.1007/s00011-006-5208-x.

50. Dumortier H, Monneaux F, Jahn-Schmid B, Briand JP, Skriner K, Cohen PL, et al. B and T cell responses to the spliceosomal heterogeneous nuclear ribonucleoproteins A2 and B1 in normal and lupus mice. J Immunol. 2000 165(4):2297-305. https://doi.org/10.4049/jimmunol.165.4.2297.

51. Fatenejad S, Brooks W, Schwartz A, Craft J. Pattern of anti-small nuclear ribonucleoprotein antibodies in MRL/Mp-lpr/lpr mice suggests that the intact U1 snRNP particle is their autoimmunogenic target. J Immunol. 1994; 152(11):5523-31.

52. Nickerson KM, Christensen SR, Shupe J, Kashgarian M, Kim D, Elkon K, et al. TLR9 regulates TLR7- and MyD88-dependent autoantibody production and disease in a murine model of lupus. J Immunol. 2010;184(4):1840-8. https:// doi.org/10.4049/jimmunol.0902592.

53. Riva F, Bonavita E, Barbati E, Muzio M, Mantovani A, Garlanda C. TIR8/ SIGIRR is an interleukin-1 receptor/toll like receptor family member with regulatory functions in inflammation and immunity. Front Immunol. 2012;3:322.

54. Shi J, Knevel $R$, Suwannalai $P$, van der Linden MP, Janssen GM, van Veelen PA, et al. Autoantibodies recognizing carbamylated proteins are present in sera of patients with rheumatoid arthritis and predict joint damage. Proc Natl Acad Sci U S A. 2011;108(42):17372-7. https://doi.org/10.1073/pna s.1114465108.

55. Poulsen TBG, Damgaard D, Jørgensen MM, Senolt L, Blackburn JM, Nielsen $\mathrm{CH}$, et al. Identification of nNovel nNative aAutoantigens in rRheumatoid aArthritis. Biomedicines. 2020;8(6):141.

56. Trouw LA, Rispens T, Toes REM. Beyond citrullination: other posttranslational protein modifications in rheumatoid arthritis. Nat Rev Rheumatol. 2017;13(6):331-9. https://doi.org/10.1038/nrrheum.2017.15.

57. Konig MF, Abusleme L, Reinholdt J, Palmer RJ, Teles RP, Sampson K, et al. Aggregatibacter actinomycetemcomitans-induced hypercitrullination links periodontal infection to autoimmunity in rheumatoid arthritis. Sci Transl Med. 2016;8(369):369ra176.

58. Jenning M, Marklein B, Ytterberg J, Zubarev RA, Joshua V, van Schaardenburg D, et al. Bacterial citrullinated epitopes generated by. Ann Rheum Dis. 2020;79(9):1194-202. https://doi.org/10.1136/annrheumdis-201 9-216919.

59. Yan-Sanders Y, Hammons GJ, Lyn-Cook BD. Increased expression of heterogeneous nuclear ribonucleoprotein A2/B1 (hnRNP) in pancreatic tissue from smokers and pancreatic tumor cells. Cancer Lett. 2002;183(2): 215-20. https://doi.org/10.1016/S0304-3835(02)00168-4.

60. Zhou J, Mulshine JL, Ro JY, Avis I, Yu R, Lee JJ, et al. Expression of heterogeneous nuclear ribonucleoprotein A2/B1 in bronchial epithelium of chronic smokers. Clin Cancer Res. 1998;4(7):1631-40.

61. Egerer K, Feist E, Burmester GR. The serological diagnosis of rheumatoid arthritis: antibodies to citrullinated antigens. Dtsch Arztebl Int. 2009;106(10): 159-63. https://doi.org/10.3238/arztebl.2009.0159.

62. Seegobin SD, Ma MH, Dahanayake C, Cope AP, Scott DL, Lewis CM, et al. ACPA-positive and ACPA-negative rheumatoid arthritis differ in their requirements for combination DMARDs and corticosteroids: secondary analysis of a randomized controlled trial. Arthritis Res Ther. 2014;16(1):R13. https://doi.org/10.1186/ar4439.

63. Gavrilă Bl, Ciofu C, Stoica V. Biomarkers in rheumatoid arthritis, what is new? J Med Life. 2016;9(2):144-8.

64. Hua C, Daien Cl, Combe B, Landewe R. Diagnosis, prognosis and classification of early arthritis: results of a systematic review informing the 2016 update of the EULAR recommendations for the management of early arthritis. RMD Open. 2017;3(1):e000406. https://doi.org/10.1136/rmdopen-2 016-000406.

65. Trouw LA, Mahler M. Closing the serological gap: promising novel biomarkers for the early diagnosis of rheumatoid arthritis. Autoimmun Rev. 2012;12(2):318-22. https://doi.org/10.1016/j.autrev.2012.05.007.
66. Knuckley B, Causey CP, Jones JE, Bhatia M, Dreyton CJ, Osborne TC, et al. Substrate specificity and kinetic studies of PADs 1, 3, and 4 identify potent and selective inhibitors of protein arginine deiminase 3. Biochemistry. 2010; 49(23):4852-63. https://doi.org/10.1021/bi100363t.

67. Tarcsa E, Marekov LN, Mei G, Melino G, Lee SC, Steinert PM. Protein unfolding by peptidylarginine deiminase. Substrate specificity and structural relationships of the natural substrates trichohyalin and filaggrin. J Biol Chem. 1996;271(48):30709-16. https://doi.org/10.1074/jbc.271.48.30709.

68. Hoffmann MH, Tuncel J, Skriner K, Tohidast-Akrad M, Türk B, Pinol-Roma S, et al. The rheumatoid arthritis-associated autoantigen hnRNP-A2 (RA33) is a major stimulator of autoimmunity in rats with pristane-induced arthritis. J Immunol. 2007;179(11):7568-76. https://doi.org/10.4049/jimmunol.179.11. 7568.

\section{Publisher's Note}

Springer Nature remains neutral with regard to jurisdictional claims in published maps and institutional affiliations.
Ready to submit your research? Choose BMC and benefit from:

- fast, convenient online submission

- thorough peer review by experienced researchers in your field

- rapid publication on acceptance

- support for research data, including large and complex data types

- gold Open Access which fosters wider collaboration and increased citations

- maximum visibility for your research: over $100 \mathrm{M}$ website views per year

At $\mathrm{BMC}$, research is always in progress.

Learn more biomedcentral.com/submissions 